\title{
Evaluation of novel inducible promoter/ repressor systems for recombinant protein expression in Lactobacillus plantarum
}

\author{
Silvia Heiss, Angelika Hörmann, Christopher Tauer, Margot Sonnleitner, Esther Egger,
}

Reingard Grabherr and Stefan Heinl

\begin{abstract}
Background: Engineering lactic acid bacteria (LAB) is of growing importance for food and feed industry as well as for in vivo vaccination or the production of recombinant proteins in food grade organisms. Often, expression of a transgene is only desired at a certain time point or period, e.g. to minimize the metabolic burden for the host cell or to control the expression time span. For this purpose, inducible expression systems are preferred, though cost and availability of the inducing agent must be feasible. We selected the plasmid free strain Lactobacillus plantarum 3NSH for testing and characterization of novel inducible promoters/repressor systems. Their feasibility in recombinant protein production was evaluated. Expression of the reporter protein mCherry was monitored with the BioLector ${ }^{\circledR}$ micro-fermentation system.
\end{abstract}

Results: Reporter gene mCherry expression was compared under the control of different promoter/repressor systems: $P_{\text {lacA }}$ (an endogenous promoter/repressor system derived from L. plantarum 3NSH), $P_{\text {xylA }}$ (a promoter/repressor system derived from Bacillus megaterium DSMZ 319) and $P_{\text {lacsynth }}$ (synthetic promoter and codon-optimized repressor gene based on the Escherichia coli lac operon). We observed that $\mathrm{P}_{\text {lacA }}$ was inducible solely by lactose, but not by non-metabolizable allolactose analoga. $P_{x y l A}$ was inducible by xylose, yet showed basal expression under non-induced conditions. Growth on galactose (as compared to exponential growth phase on glucose) reduced basal mCherry

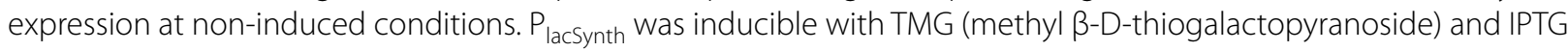
(isopropyl $\beta$-D-1-thiogalactopyranoside), but also showed basal expression without inducer. The promoter $P_{\text {lacsynth }}$ was used for establishment of a dual plasmid expression system, based on T7 RNA polymerase driven expression in $L$. plantarum. Comparative Western blot supported BioLector ${ }^{\circledR}$ micro-fermentation measurements. Conclusively, overall expression levels were moderate (compared to a constitutive promoter).

Conclusions: We evaluated different inducible promoters, as well as an orthologous expression system, for controlled gene expression in L. plantarum. Furthermore, here we provide proof of concept for a T7 RNA polymerase based expression system for L. plantarum. Thereby we expanded the molecular toolbox for an industrial relevant and generally regarded as safe (GRAS) strain.

Keywords: L. plantarum 3NSH, BioLector ${ }^{\circledR}$ micro-fermentation system, Orthologous expression system, T7 RNA polymerase, IPTG, Inducible expression

\footnotetext{
${ }^{*}$ Correspondence: stefan.heinl@boku.ac.at

Christian Doppler Laboratory for Genetically Engineered Lactic Acid

Bacteria, Department of Biotechnology, University of Natural Resources

and Life Sciences, Muthgasse 11, 1190 Vienna, Austria
} 


\section{Background}

Lactobacillus plantarum is a versatile lactic acid bacterium that is generally regarded as safe (GRAS). It inhabits diverse ecological niches and exhibits probiotic characteristics [42]. L. plantarum is often used as starter or adjunct culture in fermented food and feed production processes like for sausages, cheeses, fermented vegetables, and grass or corn silage [10, 36, 37]. Due to its high oxygen tolerance and robustness in natural fermentation processes, L. plantarum has gained increasing interest also as a host for recombinant protein expression and thus, its use in biotechnological applications is steadily growing $[1,20,41]$. Research involves genomics, transcriptomics, cell engineering and evolutionary strain optimization $[9,37]$ e.g. for bulk production of chemicals, metabolites and enzymes $[23,28]$ as well as for in situ delivery of vaccines $[8,11,12,32,50]$. Anti-microbial features, such as plantaricin production, are also of growing importance [33].

Specific gene regulatory elements like promoters are a prerequisite for efficient transcription of recombinant genes in any host organism. Accordingly, several constitutive promoters and shuttle vector systems have been established [38, 43, 44, 47]. Often, constitutive expression is preferred, for example for in situ delivery of recombinant proteins in the human body, or when steady-state gene expression is required [38]. Contrarily, constitutive promoters do not allow regulation of gene expression and production levels are directly linked to cellular growth. Continuous transcription throughout the fermentation process poses a limit to the expression of foreign proteins, which are potentially toxic to the host cell or exhibit excessive metabolic burden.

An alternative strategy is to use substrate dependent promoters that can be induced after a certain cell density has been reached. Several inducible promoters for L. plantarum have been described in the literature. The nisin-controlled gene expression (NICE) system is inducible with the bacteriocin nisin from Lactococcus lactis and was established also for L. plantarum [25]. However, the expression is not tightly regulated except if the target expression cassette is integrated into the host's chromosome [34]. The pSIP system comprises a well-established inducible promoter system and is based on the induction of promoters from Lactobacillus sakei with an inducing peptide [46]. More recently, another inducible promoter based on manganese starvation was described for $L$. plantarum NC8 [3].

Yet, numerous other substrate induced promoterrepressor systems are present in $\mathrm{LAB}$ and other bacteria that eventually may serve to efficiently control transgene expression. Lactobacillus plantarum contains a lac operon which was expected to be regulated similarly as the well-studied lac-operon of Escherichia coli, where the lac-operon comprises the genes $\operatorname{lac} Z$ ( $\beta$-galactosidase), lac $Y$ (lactose permease), lacA (transacetylase) and lacI (repressor). Allolactose is the natural inducer of the lac-operon. In E. coli, thio-galactosides such as IPTG (isopropyl $\beta$-D-1-thiogalactopyranoside) and TMG (methyl $\beta$-D-thiogalactopyranoside) are the most commonly used inducers in industrial production processes.

We established a synthetic inducible promoter system based on the E. coli derived lac-operon, which we adapted for L. plantarum in the high copy number shuttle vector pCDLbu1 $[15,43]$. Based on the inducible synthetic system, we designed and constructed an artificial T7 RNA polymerase regulated dual plasmid expression system and demonstrated its applicability in L. plantarum 3NSH. Additionally, we tested endogenous lac-operon regulatory sequences from L. plantarum $3 \mathrm{NSH}$. This strain is derived from L. plantarum CD033, which was cured of its native plasmid [17]. Plasmid free strains are preferable expression hosts, since native plasmids sometimes interfere with expression vector replication.

Another well-known regulated system is the xylose operon and the xylose promoter/repressor gene from Bacillus megaterium, which is well established for Grampositive bacteria, and was already used for high yield production of secretory levansucrase in B. megaterium YYBm1 [22] and dextransucrase in B. megaterium MS941 [26]. Moreover, three different recombinant proteins in Brevibacillus choshinensis SP3 under the control of $\mathrm{P}_{x y l A}$ from $B$. megaterium have been reported [5]. D-xylose is metabolized by two intracellular enzymes: the D-xylose isomerase (XylA) and the D-xylose kinase (XylB). $\mathrm{D}$-xylose can be transported into the cell by two different mechanisms. One mechanism involves a D-xylose$\mathrm{H}^{+}$or $-\mathrm{Na}^{+}$symporter $(x y l T)$ and is regulated by CcpA [40]. Another mechanism is driven by ATP and consists of a high-affinity xylose transporter system involving a periplasmic binding protein. For three species of facultative hetero-fermentative lactobacilli, Lactobacillus pentosus, L. plantarum, and Lactobacillus casei it was shown that EII ${ }^{\text {Man }}$ complex of the phosphoenolpyruvate (PEP): D-mannose phosphotransferase system (PTS) is involved in D-xylose transport via facilitated diffusion [4]. Posno and co-workers [35] reported that L. plantarum does not metabolize D-xylose. For its use as an inducer, this is an advantage, since D-xylose is not degraded and keeps the level of induction constant throughout the process.

In this study, we present the establishment and characterization of different inducible promoter/repressor systems (and their respective inducer) in the high copy number pCDLbu1 shuttle vector for L. plantarum $3 \mathrm{NSH}$. We used mCherry as reporter protein and expression 
levels were analyzed with the BioLector ${ }^{\circledR}$ micro-fermentation system and confirmed by Western blot immunodetection. Furthermore, we established an inducible T7 RNA polymerase based system for regulated recombinant gene expression. Summarizing, we present expression plasmids with a set of novel inducible promoters, and expand the toolbox for recombinant protein expression in L. plantarum.

\section{Results and discussion}

Different inducible promoter systems were characterized and tested in the plasmid free strain L. plantarum $3 \mathrm{NSH}$ [17]. Comparative studies were carried out regarding bacterial growth rates, level of reporter gene expression, effect of inducer and behavioral differences due to varying carbon sources. BioLector ${ }^{\circledR}$ micro-fermentations were established. FlowerPlates (with or without optodes for low $\mathrm{pH}$ and dissolved oxygen) for detection of biomass (calculated optical density) and fluorescence were used for L. plantarum fermentation and analysis.

Besides promoter elements and transcription initiation, other factors additionally influence the level of protein expression. Such are terminators, untranslated regions, plasmid copy numbers and the protein itself (amino acids, folding, and toxicity). In our experimental setup, we chose the ribosomal binding site (RBS) and the spacer between the RBS and start codon to be identical for all promoter constructs (Fig. 1), in order to exclude

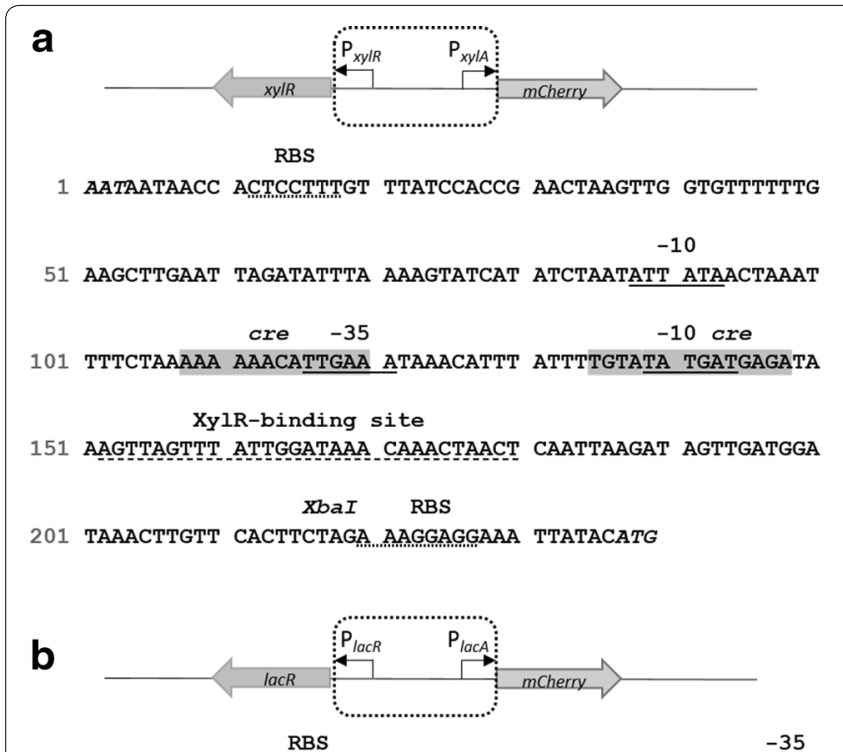

1 CACAGTGGAA GACTCCTITIC GTCAAACAAG TTACTAAACA GATGATTACC

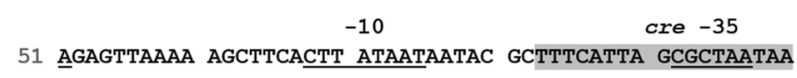

LacR-

101 AAgCGgTAAT GAATATAAAC AAAACGTAAA TAGTGTTTAC TGATATTTAG

binding site -35 cre -10

151 TAATTATTTT AGTAAAACGG GTTACATTCG TAAATGAAAG CGCTTATCAT

XbaI RBS

201 AAGAGCTGTT AAAGCGTAAT TAAGTTTCTA GAAAGGAGGA AATTATACAT
C

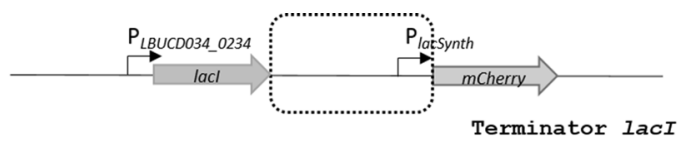

1 TAATTTGACC GGCTTGATAT ACAAAAAAGG TTTCAGTCAG ACAATCTCTG

51 ATTGAAACCT TTTTATTTTA AATAGGTGTG ATCGTTTTGA TGGATCAACG

101 CTTCAACCAA ACCCGTTACC GGCAAATTTT CCCCCAGAAT TGGACCAACA

151 TTAAGGTCAC CAATAATCCC AATCAGCTAA GAAATGCCCT GCAAAACTTT

$\mathrm{O}_{1} \quad$ LacI-binding site

201 TGGCAGCACG GCAATCAGAA TTGTTATCCG CTCACAATTT AAGTGTTCTC

-35 $P_{\text {LBUCD034_2083 }}-10$

251 TTGCCAAAAA AAGCGAATGG GTGTATACTA ATAACGCTGT TCGTTAATCG

$O_{I D}$ LacI-binding site XbaI RBS

301 AATTAAAGCC AATTGTGAGC_GCTCACAATP GTCTAGAAAG GAGGAAATTA

351 TACATG

$251 G$

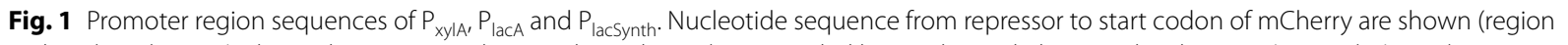
within dotted square). The mCherry start codon is indicated in italics, preceded by an identical ribosome binding site (RBS; italics) an Xbal restriction site (bold) and an identical $9 \mathrm{nt}$ spacer sequence was introduced upstream of mCherry start codon. The -35 and -10 promoter region were identified (SoftBerry, BPROM) and are underlined. Primer binding sites for negative controls (for construction of negative controls without promoter) are underlined in dashed line. a $\mathrm{P}_{\mathrm{xyI} I \mathrm{~A}}$; promoter of xyIA gene from B. megaterium DSMZ 319 and promoter of repressor XyIR. Operator sequences for XyIR binding are underlined; cre sites (catabolite-responsive element) are highlighted. $\mathbf{b} \mathrm{P}_{\text {lacA }}$; endogenous promoter of LacA from L. plantarum $3 \mathrm{NSH}$ and promoter of repressor LacR. LacR-binding site was identified (RegPrecise) and underlined, and putative cre-sites are highlighted. c $\mathrm{P}_{\text {lacSynth; }}$ promoter $\mathrm{P}_{2083}$ from L. buchneri CD034 with artificially integrated operator binding sites with recommended distance of 93 nt $\left(\mathrm{O}_{1}\right.$ and $\mathrm{O}_{\mathrm{iD}}$ from $\mathrm{E}$. coli) are underlined (dotted line), terminator of lacl is underlined (solid line) 
any translational effects on mCherry expression caused by different RBSs. However, the promoter consensus sequences (including the -35 and -10 region) were specific for each tested promoter.

The heterologous promoter $\mathrm{P}_{\mathrm{xylA}}$ is inducible by xylose The promoter fragment $P_{x y l A}$ and the repressor gene cassette XylR were amplified from B. megaterium DSMZ 319 genomic DNA with primers listed in Table 1. Nucleotide sequences of promoters $\mathrm{P}_{\mathrm{xylA}}$ and promoter $\mathrm{P}_{\mathrm{xylR}}$ to start codon of mCherry are shown in Fig. 1a, where promoter, RBS, cre (catabolite-responsive element)-sites and XylR binding site are indicated. The xyl-repressor binding motif is indicated according to Stammen and colleagues [45].
Description of the operon and its regulation was presented by Schmiedel and colleagues [40]. Preliminary tests were performed with native RBS from XylA from

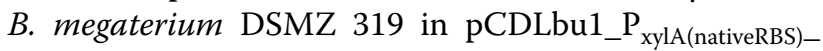
mCherry. The comparison of RBS and spacer sequence of $\mathrm{P}_{\text {xylA (native RBS) }}$ and $\mathrm{P}_{\text {xylA }}$ is shown in Additional file 1: Figure $\mathrm{S} 1$. We compared mCherry expression with native RBS to the uniform and artificial SOPT\#9 spacer RBS and sequence (5'-TCTAGAAAGGAGGAAATTATACATG-3', from XbaI to start codon), which was established for L. plantarum CD033 [47]. SOPT\#9 was used for all constructs and allowed comparison of mCherry expression apart from translational influences. Interestingly, we found that SOPT\#9 lead to slightly higher expression levels compared to the native $x y l \mathrm{~A}$ RBS and

Table 1 List of primers used in this study

\begin{tabular}{|c|c|}
\hline Name & $5^{\prime}-3^{\prime}$ Sequence \\
\hline PlacSynth_Sacl_EcoRI_F & GATGACGAGCTCGAATTCTGGTCTTTATTCTTCAA \\
\hline M13_R_Nhel & CGACGAGCTAGCAGCCAGGAAACAGCTATGACC \\
\hline mCherry_RBS_Xbal & GCTGCTICTAGAAAGGAGGAAATTATACATGTTATCAAAGGGTGAAGAAG \\
\hline mCherry_R_BamHI & CGTCGTGGATCC TTATCACTTGTATAATTCATCCATACC \\
\hline Tldh_amp_R_Pstl & CTGCTGCTGCAGAAAAAGATTAAAAAAGCCGCTGC \\
\hline mCherry_seq_R & TGGACGACCTTCACCTTCAC \\
\hline mCherry_seq_F & AACGTATGTACCCAGAAGATG \\
\hline CAT_seq2_back & TACATCATTCTGTTTGTGATGG \\
\hline B_mega_XylOP_out_F & AACATATAAACAGCCAGTTGCC \\
\hline B_mega_XylOP_R(Spel, Scal, BamHI) & GTAGTAGGATCCAGTACTAGITTCCCCCTTTGATTTAAGTG \\
\hline mCherry_w/O_RBS_Xbal & CGTCGIICTAGAATGTTATCAAAGGGTGAAGAAGATAAC \\
\hline p256_miniori_for & CATCATAAGCTTCCCGCACGCATAGCGGTGC \\
\hline B_mega_XylOP_F_Mfel, Kpnl & GTAGTACAATTGGGTACCAAGGTGAGGGTGGAGACAG \\
\hline Bmega_XylR_newRBS_Xbal_Phos_R & GTATAATTTCCTCCTT $\underline{\text { TCTAGAAGTGAACAAGTTTATCCAT }}$ \\
\hline mCherry_Phos_F & ATGTTATCAAAGGGTGAAGAAG \\
\hline B_mega_XylOP_seq_F & CAATTCCGATATTAATACTGATG \\
\hline B_mega_XylOP_seq_R & CTAGTCGGAATAGGAATTTGTG \\
\hline Lacl_Lplant_F_Sacl & AGCAGCGAGCTCCCTAATAGAACTGCGGTGGTC \\
\hline Lacl_Lplant_R_Xbal & AGCAGCICTAGAAACTTAATTACGCTTTAACAGC \\
\hline lacR_Gal_seq_R & AATTGAAGTGATGCGGGTCTG \\
\hline lacR_Gal_seq_F & AATTGCGCCAGCTAACACCC \\
\hline T7_RNAP_LP_RBS & CAGCAGTCTAGATCCTAAAGGAGG \\
\hline T7_RNAP_LP_Term_R_Sall & CAGCAGGTCGACTTGATATACAAAAAAGG \\
\hline M13_2_F & TTGTAAAACGACGGCCAGTG \\
\hline T7-Promoter_Sacl & 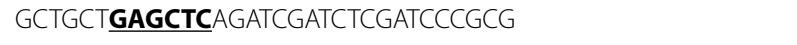 \\
\hline T7-Terminator_Sall & GCTGCT GTCGACTCCGGATATAGTTCCTCCTTTC \\
\hline ery_back_Kasl & CATCATGGCGCCTCCGATTGCAGTATAAATTTAACG \\
\hline oripE194_seq_back & AATCAAATCGGTATAAATCTGAC \\
\hline Ery_F_Nhel & CATCATGCTAGCTCCGATTGCAGTATAAATTTAACG \\
\hline Pempty_Sacl_R & TAGTAGICTAGAGCTCGAATTCACTGGCCGTCG \\
\hline mCherry_RBS_Sacl_F & GCTGCTGAGCTCAAGGAGGAAATTATACATGTTATCAAAGGGTGAAGAAG \\
\hline
\end{tabular}

Restriction sites are underlined and highlighted in bold or italics 
spacer sequence (data not shown) and was well suited for recombinant protein expression in L. plantarum $3 \mathrm{NSH}$. Parental rolling circle replicating plasmid pCDLbu1 is shown in Fig. 2a. The final shuttle vector pCDLbu1_ $\mathrm{P}_{\text {xylA_}} \mathrm{mCherry}$ for $\mathrm{P}_{\text {xylA }}$ regulated mCherry expression is depicted in Fig. 2b.

Cells were grown on selective media with either glucose (Fig. 3a, c) or galactose (Fig. 3b, d) as main carbon source, induced with xylose (or absence of inducer) after $2 \mathrm{~h}$ and analyzed. Figure $3 \mathrm{a}, \mathrm{b}$ show relative fluorescence units (RFUs) of mCherry expression (with or without induction) under control of $\mathrm{P}_{\mathrm{xylA}}$ for $23 \mathrm{~h}$. In related literature the used amount of xylose added as inducer varies from $0.5 \%(w / v)$ in Bacillus megaterium to 0.2 and $2 \%$ in $B$. subtilis $[2,22,26]$. Figure 3a shows that the addition of 0.2 or $2 \%$ xylose in MRS medium with glucose as main carbon source showed no effect on mCherry expression as compared to non-induced conditions. Figure $3 \mathrm{~b}$ indicates that growth on galactose and induction with 0.2 or $2 \%$ xylose led to enhanced expression of mCherry expression during exponential growth phase. Moreover, basal expression in medium containing $2 \%$ galactose as main carbon source was repressed during the exponential phase (Fig. 3b), as compared to growth on glucose (Fig. 3a).
Lactobacillus plantarum 3NSH is incapable of metabolizing xylose (data not shown), but xylose is efficiently transported into the cell. The use of this promoter/repressor-system in lactobacilli was tested here for the first time.

Additionally, we tested a negative control (expression plasmid without the promoter/repressor fragment), which did not show any mCherry expression (Fig. 3a, b, solid line). Thus, basal expression was caused by weak repression of $\mathrm{P}_{x y l A}$ through inefficient XylR repressor binding and not by any putative additional regulatory sequences present on the plasmid.

In B. megaterium, the presence of glucose was shown to cause repression of $\mathrm{P}_{\text {xylA }}$ by CcpA (catabolite control protein A) binding $\mathrm{cre}$-sites within the promoter region and the $x y l A$ gene [13]. The $x y l A$ promoter in our context (Fig. 1a) contains two cre-sites, which were termed cre ${ }^{*}-35.5$ and (cre)-8.5 (a cre-like site) by Gösseringer and coworkers [13] who also showed that in B. megaterium the cre +130.5 (within $x y l A$ sequence) and cre $^{*-}$ 35.5 are simultaneously bound by CcpA, which results in looping of intervening DNA and tight repression of $x y l A$ transcription. Interestingly, we did not observe catabolite repression of mCherry expression by the presence of glucose with our construct (Fig. 3a). A reason for

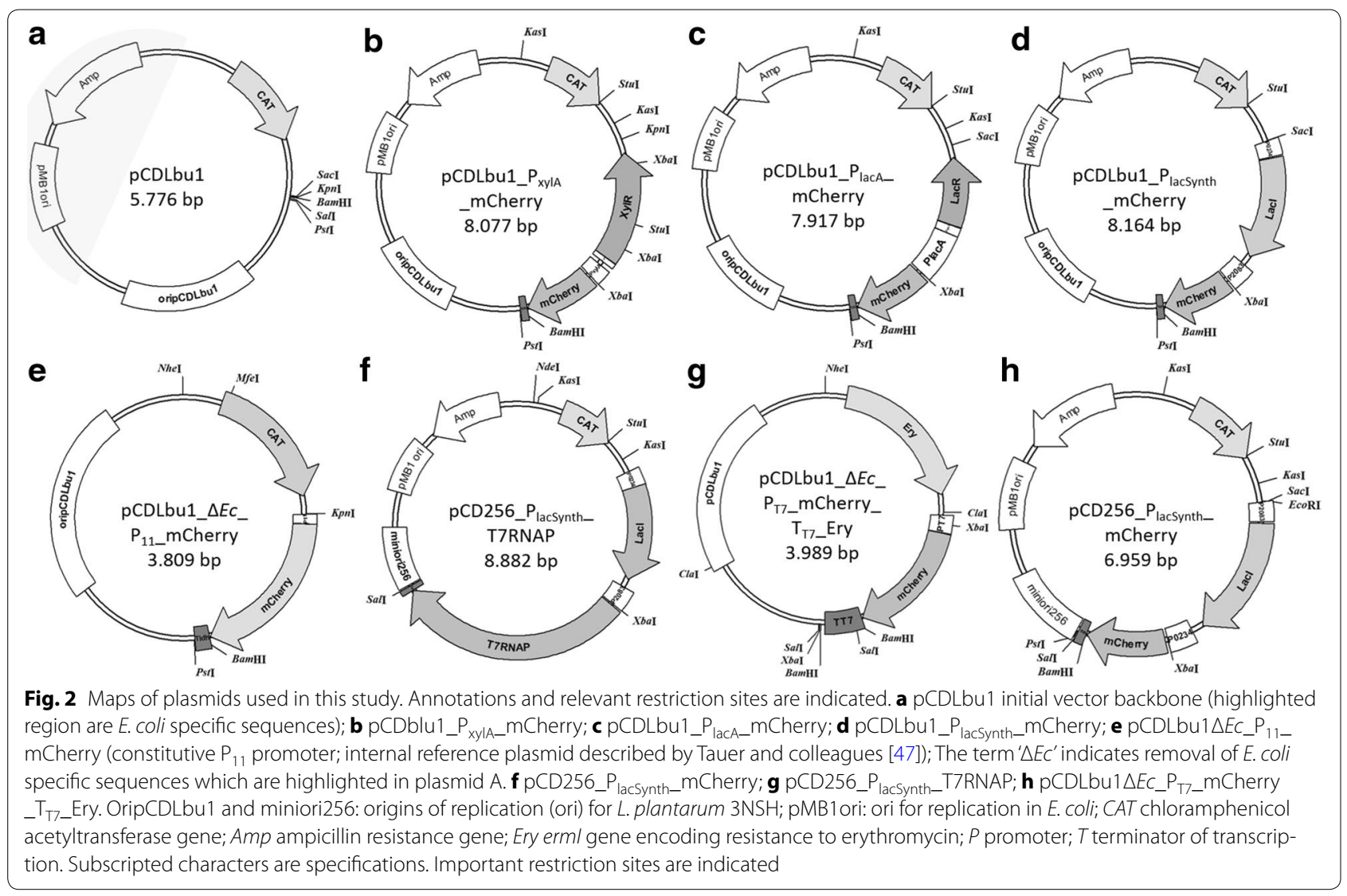



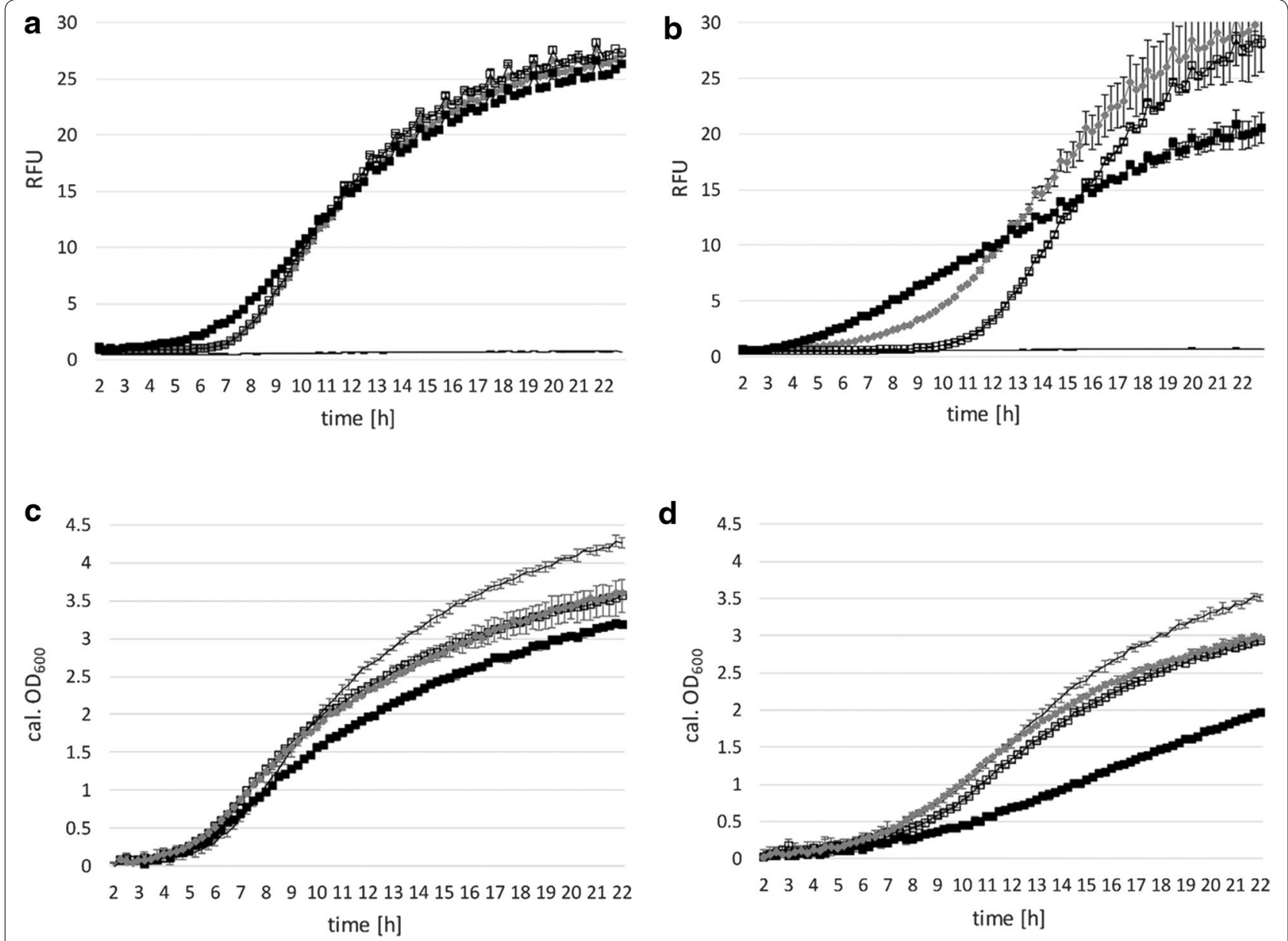

Fig. 3 Promoter characteristics of $P_{x y l A}$ and growth behavior. a, c MRS medium with glucose and $5 \mathrm{\mu g} \mathrm{ml}^{-1} \mathrm{CM} ; \mathbf{b}$, d MRS medium with galactose and $5 \mu \mathrm{g} \mathrm{ml}^{-1} \mathrm{CM}$, mean values of four replicates are given and standard deviations are indicated. Filled square induced $2 \%$ xylose. Filled diamond induced $0.2 \%$ xylose. Square non-induced. Solid line negative control. a,b specific expression levels of mCherry under control of $P_{x y l A}$ after induction with 2, $0.2 \%$ xylose (or no induction) after $2 \mathrm{~h}$ in BioLector ${ }^{\circledR}$ micro-fermentation. Change of mCherry expression (RFUs, relative fluorescent units) over time (hours) of $\mathrm{P}_{\text {xylA }}$ mediated expression in comparison to the negative control is shown. $\mathbf{c}$ and $\mathbf{d}$ corresponding calculated $\mathrm{OD}_{600}$ values

this could be the lack of cre +130.5 within the mCherry gene, hence, multimer formation and efficient catabolite repression is prevented. Another explanation for the relatively strong basal expression level could be that glucose inhibits DNA binding by XylR and acts as a low-efficiency inducer for XylR as reported by Dahl and co-workers [6]: similar structure of xylose and glucose enable both sugars to utilize the same binding site on repressor XylR.

Plasmid pCDLbu1_P xylA_mCherry containing cells only showed minor growth differences on selective medium with either glucose or galactose (Fig. 3c, d). Growth on galactose slightly increased mCherry expression and decreased basal expression levels, resulting in an improved regulation of the system during exponential phase (Fig. 3b). We hypothesize that galactose interferes less with XylR mediated repression in L. plantarum than glucose and, hence, leads to improved repression of mCherry expression.

Lactobacillus plantarum 3NSH does not metabolize xylose, but effective transportation of xylose was demonstrated through inducibility of expression. The L. plantarum WCFS1 complete genome sequence [21] suggests genes involved in transport (lp_0331, lp_0975), but no $x y l A$ or $x y l B$. Chaillou et al. [4] report that EII ${ }^{\mathrm{Man}}$ complex of the phosphoenolpyruvate (PEP): D-mannose PTS is involved in D-xylose transport via facilitated diffusion. For industrial processes, it is considered an advantage, when the inducing substance is not degraded and a constant concentration during cultivation can be maintained. In terms of plant based biomass degradation, where xylose is highly abundant, this expression regime could provide a self-inducing promoter system for the 
production of e.g. endoglucanases and xylanases, thereby increasing the rate and efficacy of substrate metabolism in ensiling processes.

\section{The endogenous promoter $P_{\text {lacA }}$ is inducible by lactose} The promoter of lacA ( $\beta$-galactosidase) and the promoter of the Lac repressor (lacR) were amplified from L. plantarum 3NSH genomic DNA with primers shown in Table 1. Figure 1b shows the nucleotide sequences of endogenous promoters $\mathrm{P}_{\text {lacA }}$ and promoter $\mathrm{P}_{\text {lacR }}$ in divergent orientation. LacR binding site, cre-site and RBS are indicated. The final shuttle vector pCDLbu1_ $\mathrm{P}_{\text {lacA- }}$ mCherry is shown in Fig. 2c.

For promoter characterization, mCherry expression under induced and non-induced conditions was monitored. Lactose as well as the non-metabolizable lactose analogues isopropyl- $\beta$-D-thiogalactopyranoside (IPTG) and thiomethyl- $\beta$-D-galactoside (TMG) were tested for induction of $\mathrm{P}_{\text {lacA }}$. IPTG and TMG failed to induce LacR controlled gene expression (data not shown). This is in contrast to previous findings, where TMG was successfully used for the induction of $ß$-galactosidase expression in L. plantarum ATCC ${ }^{\circledR} 8014^{\mathrm{TM}}$ [19]. Different sugars were tested for induction of $\mathrm{P}_{\text {lacA }}$ (including lactose, xylose, fructose, glucose, maltose, arabinose and galactose), but $\mathrm{P}_{\text {lacA }}$ was only induced with lactose.

Lactobacillus plantarum 3NSH harboring plasmid pCDLbu1_P $\mathrm{P}_{\text {lacA_}}$ mCherry were grown on selective media either containing $2 \%$ glucose or $2 \%$ galactose as carbon source and were induced with 0.5 or $2 \%$ lactose after $2 \mathrm{~h}$. Induction of mCherry expression with lactose was weak, but slight increase of RFUs was observed upon the addition of 0.5 or $2 \%$ lactose on glucose (Fig. 4a), but was not observed on galactose (Fig. 4b). Contradicting the observation by Hasan and Durr [14], we did not detect full repression in the presence of glucose.

Catabolite inhibition through diminished entry of lactose into the cell could explain why calculated $\mathrm{OD}_{600}$ does not increase with additional carbon source (Fig. 4c, d). Negative control (without the promoter/repressor fragment; Fig. 4a, b, solid line) grew weaker on galactose without obvious reason.

Compared to the negative control and compared to growth on glucose, minor growth impairment of the plasmid containing cells on $2 \%$ galactose (Fig. 4d) or $2 \%$ lactose (Fig. 4f) as carbon source was observed. Figure $4 \mathrm{e}, \mathrm{f}$ show mCherry expression and growth on selective MRS medium with 0.5 and $2 \%$ lactose as the sole carbon source and inducer. In contrast to data presented in Fig. 4a, mCherry expression increases, showing the catabolite repressive effect of glucose and galactose on $\mathrm{P}_{\text {lacA }}$ or on cell entry of lactose. An increase from 0.5 to $2 \%$ lactose increases expression (Fig. 4e) and growth
(Fig. 4f). However, obtained calculated $\mathrm{OD}_{600}$ values on galactose and induction with lactose (Fig. 4c, f, filled circle) were comparable and did not increase, albeit the twofold amount of carbon source was available.

The chromosomally encoded lac locus (lp_3468, lp_3469 and lp_3470) as well as existence of a second lac locus (lp_3483, lp_3484), as indicated for L. plantarum WCSF1 genomic sequence [21], might interfere with usage of lactose as inducer, since L. plantarum $3 \mathrm{NSH}$ can utilize lactose as carbon source. The expression levels of mCherry under control of endogenous $\mathrm{P}_{\text {lacA }}$ were rather low on glucose or galactose, but when lactose was used as sole carbon source and inducer, expression levels improved significantly.

\section{The synthetic promoter $P_{\text {lacsynth }}$ is inducible by IPTG}

The lacA promoter and the lacI promoter/repressor are widely used for many different $E$. coli based expression systems and many mutant versions are available [48]. Therefore, we synthesized a DNA template consisting of the promoter $\mathrm{P}_{2083}$ of L. buchneri CD034 gene LBUCD034_2083 [16], containing two operator binding sites of the $E$. coli LacI repressor. We inserted a codon optimized version of the $E$. coli LacI repressor gene (Additional file 2: Figure S2) under control of the constitutive promoter $\mathrm{P}_{0234}$ of the L. buchneri CD034 gene LBUCD034_0234 [16]. Operator binding sites $\left(\mathrm{O}_{1}\right.$ and $\mathrm{O}_{\mathrm{id}}$ ) for Lac repressor binding were selected according to Oehler and colleagues [30] and integrated into $\mathrm{P}_{2083}$. In E. coli, a third operator binding site $\left(\mathrm{O}_{2}\right)$ is encoded within the coding sequence of lacA [31]. This downstream cisacting regulative sequence is involved in DNA bending and interaction with LacI multimers. But because integration of $\mathrm{O}_{2}$ sequence into the mCherry coding sequence was not realizable, $\mathrm{O}_{2}$ was not included in our constructs.

A synthetic regulative element for mCherry expression $\left(\mathrm{P}_{0234}\right.$ lacI_ $\mathrm{P}_{2083}-m$ Cherry) was constructed and promoter sequence and regulative elements are shown in Fig. 1c. LacI binding sites, operator binding sites $\left(\mathrm{O}_{1}\right.$ and $\mathrm{O}_{\mathrm{id}}$ ), RBS and $\mathrm{P}_{2083}$ are indicated. The consecutive construct is termed $\mathrm{P}_{\text {lacSynth }}$ and cloned into pCDLbu1 (Table 2; Fig. 2a). The resulting expression vector pCDLbu1_P $\mathrm{P}_{\text {lacSynth- }}$ mCherry is depicted in Fig. 2 d.

According to E. coli lac-operon regulation, we tested mCherry expression subsequent to induction with IPTG. Increasing concentrations in the range of 0.1 to $5 \mathrm{mM}$ $(0.1,0.5,1.0,2.0$ and $5.0 \mathrm{mM})$ were tested and showed that already 0.1 and $0.5 \mathrm{mM}$ induce $\mathrm{P}_{\text {lacSynth }}$ sufficiently in L. plantarum $3 \mathrm{NSH}$. Lower IPTG concentrations (like 0.1 and $0.5 \mathrm{mM}$ ) are in the range of common E. coli implementations. Moreover, $1 \mathrm{mM}$ IPTG led to saturated induction of mCherry in L. plantarum 3NSH (Fig. 5a, 

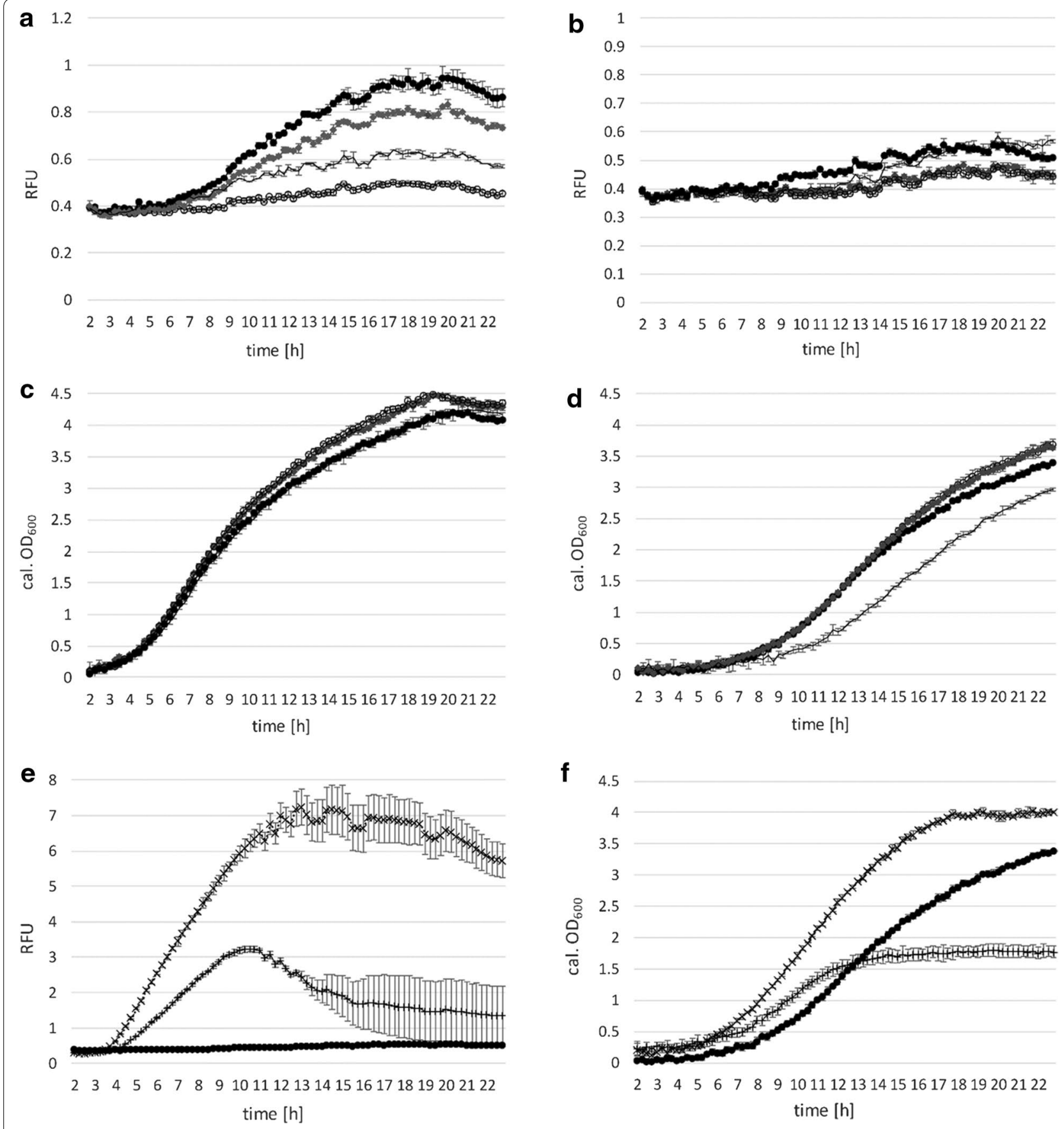

Fig. 4 Promoter characteristics of $\mathrm{P}_{\text {lacA }}$ and growth behavior. $\mathbf{a}$, c MRS medium with glucose and $5 \mu \mathrm{g} \mathrm{ml}^{-1} \mathrm{CM} ; \mathbf{b}$, d MRS medium with galactose and $5 \mu \mathrm{g} \mathrm{ml}^{-1} \mathrm{CM} ; \mathbf{e}, \mathbf{f}$ MRS medium with $5 \mathrm{\mu g} \mathrm{ml}^{-1} \mathrm{CM}$. Mean values of four replicates are given and standard deviations are indicated. Filled circle induced, $2 \%$ lactose. Filled diamond induced, $0.5 \%$ lactose. Circle non-induced. a, b specific expression levels of mCherry under control of $\mathrm{P}_{\text {lacA }}$ after induction with 0.5 and $2 \%$ lactose (or no induction) after $2 \mathrm{~h}$ in BioLector ${ }^{\circledR}$ micro-fermentation. Change of mCherry expression (RFUs, relative fluorescent units) over time (hours) of $\mathrm{P}_{\text {lacA }}$ mediated expression in comparison to the negative control is shown (solid line). c, $\mathbf{d}$ corresponding calculated $\mathrm{OD}_{600}$ values. e, f RFU and growth in selective MRS with lactose as main carbon source; $\mathrm{x}$ : induced, $2 \%$ lactose; +: induced, $0.5 \%$ lactose; filled circle induced, $2 \%$ lactose and $2 \%$ galactose as additional carbon source

b) and no further increase of expression was observable at augmented concentrations from 1 to $5 \mathrm{mM}$ (data not shown). Additionally, TMG was tested for $\mathrm{P}_{\text {lacSynth }}$ induction. We observed similar mCherry expression with induction of $17 \mathrm{mM}$ TMG compared to $1 \mathrm{mM}$ IPTG (data not shown). For L. plantarum NC2 it was shown 
Table 2 Plasmids and strains used in this study

\begin{tabular}{|c|c|c|c|c|}
\hline Plasmid & Reference & $\begin{array}{l}\text { Size } \\
\text { (bp) }\end{array}$ & Relevant characteristics & \\
\hline pET-30a & Novagen & 5400 & T7 promoter, T7 terminator & \\
\hline pE194 & {$[18]$} & 3728 & Erythromycin resistance gene (ermE) & \\
\hline pCD256 & {$[43]$} & 4790 & Low copy plasmid in L. plantarum & \\
\hline pCDLbu1 & {$[15]$} & 5776 & High copy plasmid in L. plantarum & \\
\hline pCDLbu1_P & This study & 6425 & T7 RNA polymerase specific promoter & \\
\hline 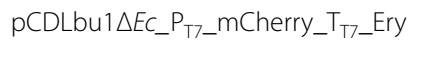 & This study & 3989 & $\begin{array}{l}\text { T7 RNA polymerase specific promoter, without sequences } \\
\text { for replication and selection in E. coli }\end{array}$ & \\
\hline 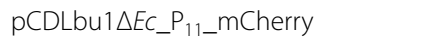 & {$[47]$} & 3809 & & \\
\hline pCD256_PlacSynth_mCherry & This study & 6959 & $\begin{array}{l}\text { Low copy plasmid; promoter } \mathrm{P}_{\text {lacsynthi }} \text { gene of interest } \\
\text { mCherry }\end{array}$ & IPTG (1 mM) \\
\hline pCD256_PlacSynth_T7RNAP & This study & 8882 & $\begin{array}{l}\text { Low copy plasmid; promoter } \mathrm{P}_{\text {lacsynthi }} \text { gene of interest T7 } \\
\text { RNA polymerase }\end{array}$ & IPTG (1 mM) \\
\hline pCDLbu1_Placsynth_mCherry & This study & 8164 & $\begin{array}{l}\text { High copy plasmid; promoter } P_{\text {lacSynthi gene of interest }} \\
\text { mCherry }\end{array}$ & IPTG (1 mM), TMG (17 mM) \\
\hline pCDLbu1_P lacA_mCherry & This study & 7917 & High copy plasmid; promoter $\mathrm{P}_{\text {lacA }}$; gene of interest mCherry & Lactose $(0.5-2 \% w / v)$ \\
\hline pCDLbu1_P ${ }_{\text {xylA_mCherry }}$ & This study & 8077 & High copy plasmid; promoter $\mathrm{P}_{x y l A}$; gene of interest mCherry & Xylose $(0.2-2 \% w / v)$ \\
\hline pCDLbu1_P $P_{\text {xylA(nativeRBS)_mCherry }}$ & This study & 8077 & $\begin{array}{l}\text { High copy plasmid; promoter } \mathrm{P}_{\text {xylA }} \text {; gene of interest mCherry; } \\
\text { native RBS and spacer sequence from B. megaterium DSMZ } \\
319 x y / A\end{array}$ & Xylose $(2 \% w / v)$ \\
\hline \multicolumn{5}{|l|}{ Strains } \\
\hline B. megaterium DSMZ 319 & DSMZ & & & \\
\hline E. coli Neb10 & NEB & & & \\
\hline L. plantarum CD033 & {$[43]$} & & & \\
\hline L.plantarum 3NSH & {$[17]$} & & Plasmid cured L. plantarum CD033 & \\
\hline
\end{tabular}

that ß-galactosides are transported via ATP driven proton motive force [19]. Induction of recombinant gene expression in a fermentation setting (BioLector ${ }^{\circledR}$ measurement) with IPTG (and TMG) is shown here for the first time in L. plantarum.

Comparative growth and induction on selective media with glucose or galactose are shown in Fig. 5c and d. Induced cultures show growth impairment (compared to the non-induced cultures) on both carbon sources, though growth on glucose as carbon source is preferred, thus leading to higher expression values and biomass (Fig. 5a, c). Overall, regarding expression levels as well as repression under non-induced conditions in both tested media variations, $\mathrm{P}_{\text {lacSynth }}$ performed better than $\mathrm{P}_{\text {xylA }}$ (Fig. 3) and $\mathrm{P}_{\text {lacA }}$ (Fig. 4). Negative control (without the promoter/ repressor fragment) showed no mCherry expression (Fig. 5; solid line). Therefore, measured expression levels correlate to induction of $\mathrm{P}_{\text {lacSynth }}$ through thiogalactosides, such as IPTG (and TMG), and basal expression might be caused by weak repression of $\mathrm{P}_{2083}$.

Consequently, we suggest limited stoichiometric availability of the repressor LacI, resulting in incomplete repression of $\mathrm{P}_{\text {lacSynth }}$ by the repressor. LacI binds to the operator sites by forming tetramers, which might not be possible if LacI availability is not sufficient [31, 49]. A stronger promoter for LacI expression (instead of $\mathrm{P}_{2083}$ ) might increase repressor levels and improve transcription control. Additionally, the operator $\mathrm{O}_{2}$ downstream of the start codon, which is originally present within the coding sequence of $\beta$-galactosidase [31], is absent within the mCherry sequence. Therefore, bending of DNA via binding of tetrameric Lac-repressor to two adjacent operators for sufficient repression is not possible. Albeit, it was reported for $E$. coli that the presence or absence of operator $\mathrm{O}_{2}$ does not have an impact on lac operon expression anyhow [27].

Apparently, on selective medium with glucose as carbon source, the ratio of induced expression to basal expression under non-induced conditions of $\mathrm{P}_{\text {lacSynth }}$ was highest compared to $\mathrm{P}_{\text {xylA }}$ or $\mathrm{P}_{\text {lacA }}$ (Figs. 3, 4). However, the $\mathrm{P}_{\text {lacSynth }}$ mediated expression after induction is still moderate and thus appropriate for the regulation of $\mathrm{T} 7$ RNA polymerase based expression of mCherry. Therefore, this synthetic promoter/repressor fragment was used for establishment of the inducible T7 system in $L$. plantarum 3NSH. 


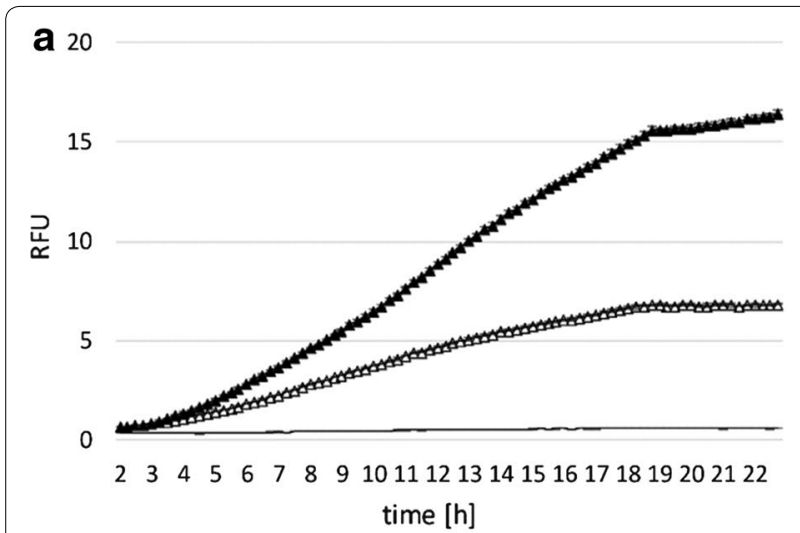

C 4.5

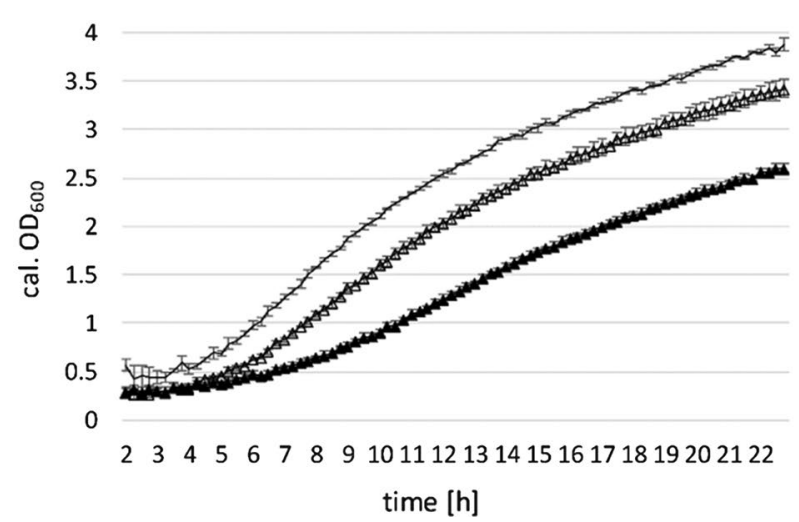

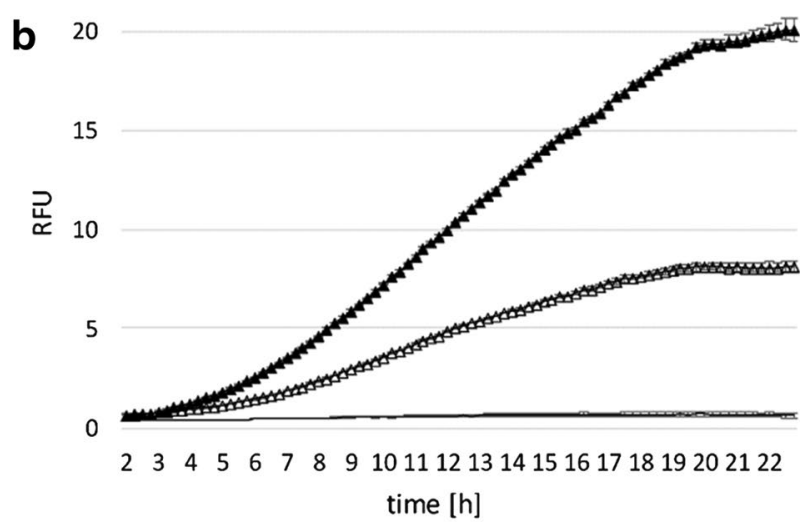

d

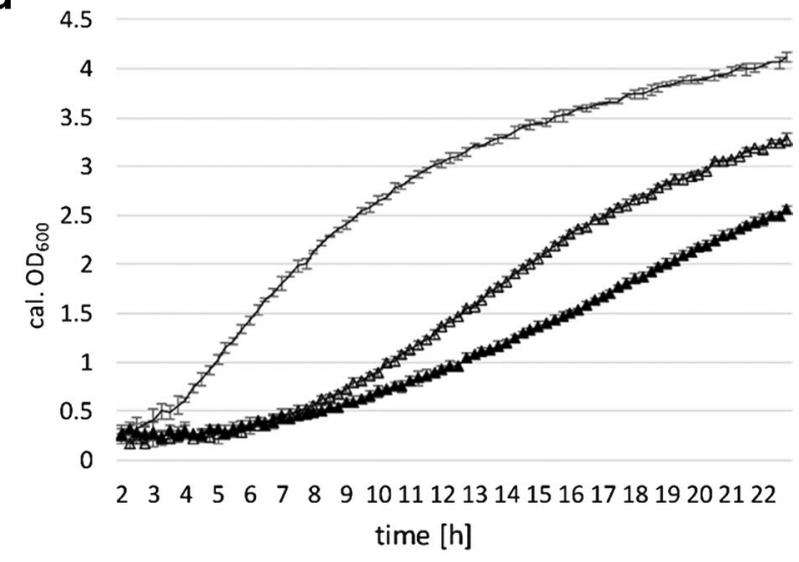

Fig. 5 Promoter characteristics of $\mathrm{P}_{\text {lacsynth }}$ and growth behavior. a, c MRS medium with glucose and $5 \mu \mathrm{g} \mathrm{ml}^{-1} \mathrm{CM} ; \mathbf{b}$, $\mathbf{d}$ MRS medium with galactose and $5 \mathrm{\mu g} \mathrm{ml}^{-1} \mathrm{CM}$, mean values of four replicates are given and standard deviations are indicated. Filled triangle induced; triangle non-induced. a, b specific expression levels of mCherry under control of $\mathrm{P}_{\text {lacsynth }}$ after induction with $1 \mathrm{mM} \mathrm{IPTG}$ (or no induction) after $2 \mathrm{~h}$ in BioLector ${ }^{\circledR}$ microfermentation. Change of mCherry expression (RFUs, relative fluorescent units) over time (hours) of $\mathrm{P}_{\text {lacsynth }}$ mediated expression in comparison to the negative control is shown (solid line). $\mathbf{c}$, $\mathbf{d}$ calculated $\mathrm{OD}_{600}$ values. Solid line negative control

T7 RNA polymerase driven mCherry expression in $L$. plantarum 3NSH

In order to establish an orthologous expression system in L. plantarum, we combined the synthetic repressor/ promoter system $\mathrm{P}_{\text {lacSynth }}$ (Fig. 1c). The adapted E. coli phage T7 RNA polymerase was applied to establish two compatible plasmids: one contained a codon optimized version of the T7 RNA polymerase (Additional file 3: Figure S3) under the control of $\mathrm{P}_{\text {lacSynth }}$ (Fig. 2f) and the second plasmid contained mCherry under control of the $\mathrm{T} 7$ RNA polymerase promoter $\mathrm{P}_{\mathrm{T} 7}$ (Fig. $2 \mathrm{~g}$ ).

For inducing T7 RNA polymerase expression, we used $1 \mathrm{mM}$ IPTG, equally to $\mathrm{P}_{\text {lacSynth }}$ induction (Fig. 5). Results of the expression experiment are shown in Fig. 6a. Induction with $1 \mathrm{mM}$ IPTG led to augmented expression of the reporter protein compared to non-induced conditions. Some basal expression of the reporter gene was detected under non-induced conditions similarly to results with $\mathrm{P}_{\text {lacSynth }}$ (Fig. 5a). Therefore, the plasmid containing
mCherry under control of the T7 RNA polymerase promoter (pCDLbu1 $\Delta E c_{-} \mathrm{P}_{\mathrm{T} 7}$ mCherry_ $\mathrm{T}_{\mathrm{T} 7}$ Ery) was tested in absence of the second plasmid, which provides the T7

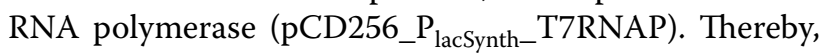
we observed no mCherry expression neither with nor without IPTG (Fig. 6a, solid line).

Although, constitutive expression using the $\mathrm{P}_{11}$ promoter was significantly higher, inducible expression based on the T7 RNA polymerase system serves as a valuable tool for regulated gene expression at moderate levels. However, growth was not affected by $\mathrm{P}_{\text {lacSynth }}$ regulating a dual plasmid expression system (Fig. 6b) compared to strains with plasmid pCDLbu1_P $\mathrm{P}_{\text {lacSynth- }}$ mCherry (Fig. 5c). This effect could also be contributed to the different plasmid backbones (pCDLbu1 and pCD256, Fig. 2d, f).

For constructing the T7 polymerase encoding plasmid, the low copy plasmid pCD256 was used (Table 2). The second plasmid (mCherry under control of $\mathrm{P}_{\mathrm{T} 7}$ ) 

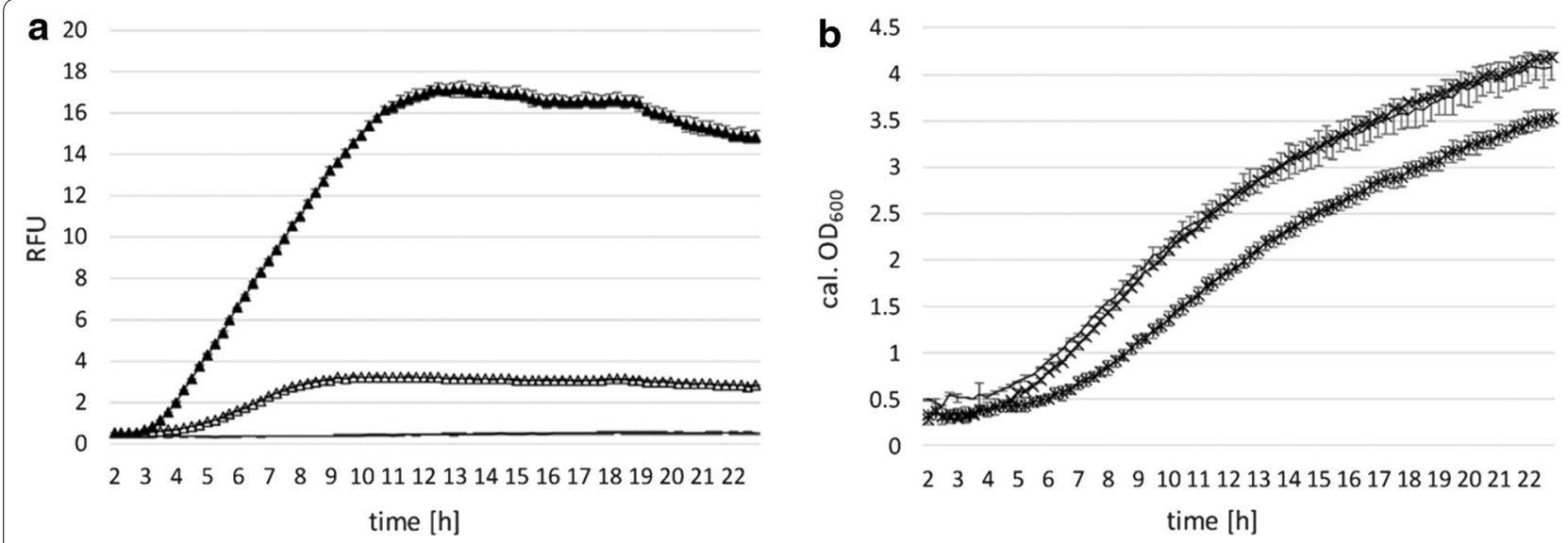

Fig. 6 Promoter characteristics and analysis of mCherry expression under control of $\mathrm{P}_{\mathrm{T} 7}$, regulated by T7 RNA polymerase under control of $\mathrm{P}_{\text {lacSynth }}$ and growth behavior. a Change of mCherry expression (RFUs, relative fluorescent units) over time (hours) regulated by T7 RNA polymerase dual plasmid system in BioLector ${ }^{\circledR}$ micro-fermentation is shown. T7 RNAP is under control of $\mathrm{P}_{\text {lacsynth }}$ and induced with 1 mM IPTG (or non-induced) after $2 \mathrm{~h}$. MRS medium with glucose either $5 \mathrm{\mu g} \mathrm{ml}^{-1} \mathrm{CM}$ or $5 \mu \mathrm{g} \mathrm{m}{ }^{-1}$ Ery (or both for the dual plasmid system). - $\mathrm{x}$-: induced; mean values of four replicates are given and standard deviations are indicated. -: non-induced; mean values of three replicates are given and standard deviations are indicated. b Calculated $\mathrm{OD}_{600}$ values. Solid line negative control $\left(n=3 ;\right.$ pCDLbu1 $\triangle E c_{-} \mathrm{P}_{\mathrm{T} 7 \_} \mathrm{mCherry} \mathrm{T}_{\left.\mathrm{T} 7 \_\mathrm{Ery}\right)}$

was established from pCDLbu1 (Table 2) without E. coli specific sequences. Thereby we generated a smaller plasmid and less genetic load. Intentionally we introduced two different origins of replication within a cell, which is known to be preferred due to plasmid incompatibility [29]. Chromosomal integration of expression cassettes has been shown previously in L. plantarum [24, 36] and would be a feasible strategy for generating a stable T7 RNA polymerase expressing host strain. Such a $L$. plantarum strain would be the basis for a new T7 based expression system in a food grade host, providing specific regulation and easy exchange of any target gene that is under control of the $\mathrm{T} 7$ promoter $\mathrm{P}_{\mathrm{T} 7}$.

\section{Comparative analysis and semi-quantitative Western blot}

The constitutive L. plantarum promoter $\mathrm{P}_{11}$ (expression vector $\mathrm{pCDLbu} 1 \Delta E c_{-} \mathrm{P}_{11}$ mCherry) served as a benchmark in a comparative analysis [38, 47]. Plasmid pCDLbu1 $\triangle E c_{-} \mathrm{P}_{11-}$ mCherry is shown in Fig. 2e. Measurements of expression levels with plasmid pCDLbu1 $\triangle E c_{-} \mathrm{P}_{11-}$ mCherry were included for intrinsic comparison, because it was previously shown to yield strongest expression of mCherry amongst several tested variants in L. plantarum CD033 [47], the parental strain of $L$. plantarum $3 \mathrm{NSH}$.

Expression levels of mCherry under control of $\mathrm{P}_{11}$ were compared to $\mathrm{P}_{\text {xylA }}, \mathrm{P}_{\text {lacA }}, \mathrm{P}_{\text {lacSynth }}$, and the $\mathrm{P}_{\text {lacSynth }}$ regulated T7 RNA polymerase, in Fig. 7a. Growth curves of producing strains and wild type are shown in Fig. 7b. MRS selective medium was used with galactose as carbon source and induction with xylose for
pCDLbu1_P $\mathrm{P}_{\text {xylA_}} \mathrm{mCherry,} \mathrm{and} \mathrm{with} \mathrm{glucose} \mathrm{plus} \mathrm{induc-}$ tion with $2 \%$ lactose for pCDLbu1_ $\mathrm{P}_{\text {lacA_}} \mathrm{mCherry}$. Growth on glucose and induction with $1 \mathrm{mM}$ IPTG was used for pCDLbu1_ $\mathrm{P}_{\text {lacSynth_}} \mathrm{mCherry}$, and subsequently for the T7 dual plasmid system. $\mathrm{P}_{11}$ driven expression (pCDLbu1 $\triangle E c_{-} \mathrm{P}_{11-}$ mCherry) is more effective (Fig. 7a). Expression levels of $\mathrm{P}_{\text {lacA }}$ were quite low for direct comparison with promoter $\mathrm{P}_{11}$, but results with $\mathrm{P}_{\text {lacA }}$ were also included in Fig. 7a and $b$.

A semi-quantitative Western blot of the inducible promoter systems at induced and non-induced conditions on glucose (Fig. 8a, c) or galactose (Fig. 8b) was performed. Sample point is indicated as vertical dotted line in Fig. 7 after $13 \mathrm{~h}$ of growth. About $5 \mu \mathrm{g}$ biomass per slot were applied, the commercially obtained positive control (mCherry-His ${ }_{6} ; 28.8 \mathrm{kDa}$ ) was applied at concentrations of 25 and 50 ng per slot. $\mathrm{P}_{11}$ samples were applied undiluted and 1:5 diluted due to stronger expression compared to the inducible systems (Fig. 7a). The Western blot shows better inducibility of the $\mathrm{P}_{\text {lacSynth }}$ system on glucose medium (Fig. 8a) whereas $\mathrm{P}_{\text {xylA }}$ induction is more distinct on galactose medium (Fig. 8b) and the T7 system is inducible on glucose (Fig. 8c). We also observed basal transcription under non-induced conditions for all compared promoter/repressor systems. This is in accordance with the BioLector ${ }^{\circledR}$ measurements.

Suitable and controllable expression levels were achieved by $\mathrm{P}_{\text {lacSynth }}$ induction with IPTG on glucose and galactose (Fig. 5a, b). Apparently, the ratio of induced expression to basal expression under non-induced conditions of $\mathrm{P}_{\text {lacSynth }}$ on selective medium with glucose as carbon source was 

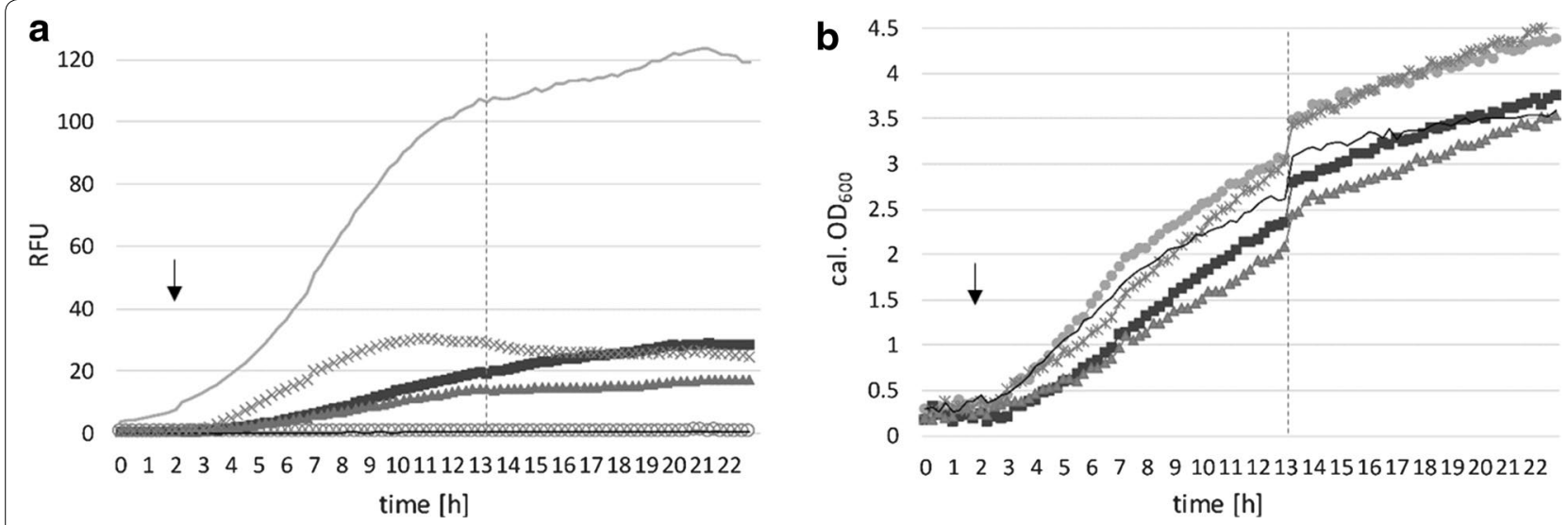

Fig. 7 Expression and growth comparison of inducible promoters to constitutive promoter. BioLector ${ }^{\circledR}$ micro-fermentation measurement for $23 \mathrm{~h}$ in selective MRS medium with glucose with low pH FlowerPlate at $30^{\circ} \mathrm{C}$ (individual values). Dotted vertical line indicates sampling point (200 $\mu$ l) for semi-quantitative Western blot, $13 \mathrm{~h}$ after start, followed by ongoing measurement, therefore $\mathrm{OD}_{600}$ curves are shifted after sampling. Arrow indicates induction time point (or absence of inducer). Solid line mCherry under control of constitutive $\mathrm{P}_{11}$ promoter (pCDLbu1 $\triangle E C_{-} \mathrm{P}_{11} \mathrm{mCherry}$ ), $-\mathrm{x}$-: T7 RNA polymerase based dual plasmid system induced with $1 \mathrm{mM} \mathrm{IPTG}$, square $P_{\text {xylA }}$ induced with $2 \%$ xylose, triangle $P_{\text {lacsynth }}$ induced with 1 mM IPTG, circle $P_{\text {lac }}$ induced with $2 \%$ lactose. a specific expression levels of mCherry under control of inducible promoters with respective inducers. b corresponding calculated $\mathrm{OD}_{600}$ values

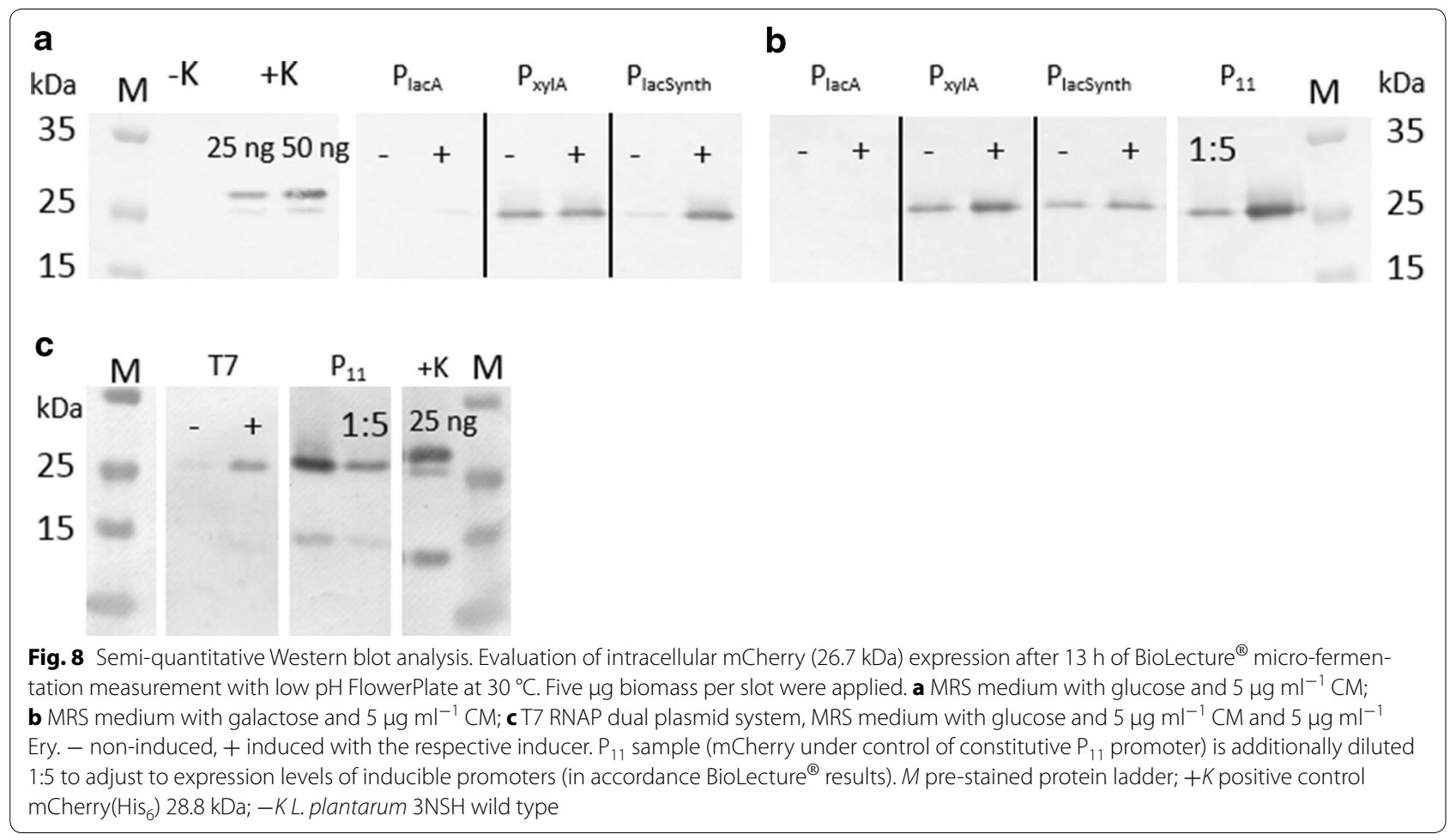

best (compared to $\mathrm{P}_{\text {lacA }}$ or $\mathrm{P}_{\text {xylA }}$ ). Moreover, the $\mathrm{P}_{\text {lacSynth }}$ mediated expression after induction was still moderate and thus, more appropriate for the regulation of T7 RNA polymerase based expression of mCherry. By using a stronger promoter for lacI, expression, repression of $\mathrm{P}_{\text {lac- }}$ Synth might be improved. If necessary, this strategy could also be applied for $x y l R$ promoter and lacR promoter. Best regulation of induced and non-induced conditions while yielding similar expression levels was achieved by T7 RNA polymerase dual plasmid based system induced with $1 \mathrm{mM}$ IPTG (Fig. 7a, 8c). The adapted T7 RNA polymerase was successfully established here for L. plantarum. 


\section{Conclusions}

In this study, we tested and compared three different promoter-repressor systems for induced recombinant protein expression (red fluorescent protein mCherry) in plasmid free L. plantarum 3NSH. Reporter gene and regulatory elements were cloned into the high copy number plasmid pCDLbu1. The endogenous LacA promoter $\left(\mathrm{P}_{\text {lacA }}\right)$ derived from L. plantarum $3 \mathrm{NSH}$ showed only weak reporter gene expression upon induction with $2 \%$ lactose, which was found to be the exclusive inducer so far. Glucose and galactose acted as repressors of $\mathrm{P}_{\text {lacA }}$. With lactose as single carbon source better expression levels were obtained. The XylA promoter $\left(\mathrm{P}_{\mathrm{xylA}}\right)$ derived from B. megaterium DSMZ 319 was tested in combination with the expression of the repressor XylR. Upon induction with $0.2-2 \%$ xylose, we measured increased mCherry expression during exponential phase, and repression under non-induced conditions with galactose as the carbon source. A synthetic promoter $\left(\mathrm{P}_{\text {lacSynth }}\right)$, based on the E. coli derived lac operon resulted in moderate expression levels after induction with IPTG and TMG. $P_{\text {lacSynth }}$ was used efficiently for the establishment of a dual plasmid system for well-regulated T7 RNA polymerase expression, and transcription of mCherry under control of the T7 RNA polymerase promoter.

Some feasible suggestions for inducible recombinant protein expression in L. plantarum 3NSH are presented in this study. Expression levels of recombinant protein are however, much lower as compared to expression levels driven by the constitutive $\mathrm{P}_{11}$ promoter. Plasmid pCDLbu1 $\triangle E E_{-} \mathrm{P}_{11 \_}$mCherry served as a benchmark and has been described previously [47]. Additionally, differences of expression in exponential phase, initiated by varying promoters, decreased during prolonged fermentation. In stationary phase (after $22 \mathrm{~h}$ ) mCherry levels of tested inducible promoters are aligned. Yet, depending on the recombinant protein (e.g. amino acid composition and post-translational modifications) or experiment outlook (e.g. short time setting or production of cell toxic products) promoters, which are inducible by conventional sugars or well-established inducers are of particular interest. Although general knowledge of recombinant protein expression (e.g. therapeutics or metabolites) in lactobacilli steadily increases, efficiency and expression levels are not yet comparable to $E$. coli based systems. Recombinant gene expression usually exerts additional metabolic burden for the host. This often results in unstable genetic constructs, inhibition of cell growth and/or plasmid loss. Therefore, inducible expression systems where transcription of the target gene can be tightly controlled are preferable. The presented expression systems might behave different in other Lactobacillus strains, the adaption of new promoter/repressor systems, and in particular a T7 RNA polymerase based expression systems for L. plantarum, is anticipated to contribute to a flexible genetic tool box for cell engineering and recombinant protein expression in lactic acid bacteria.

\section{Methods}

\section{Enzymes and gene synthesis}

All restriction and modifying enzymes, as well as Q5 DNA polymerase, were purchased from New England Biolabs (NEB). Primers (Table 1) were obtained from Integrated DNA Technologies (IDT) and phosphorylated primers were synthesized by Sigma-Aldrich.

The ribosome binding site (RBS) was identical for all constructs. Identical Shine-Dalgarno sequence (SDS) and spacer region (bold) was selected for every construct according to SOPT\#9 (5'-AAGGAGGAAATTATACATG-3'), tested for efficient mCherry (start codon underlined) expression in L. plantarum CD033 [47].

Reporter gene mCherry and the synthetic LacR repressor/promoter fragment $\left(\mathrm{P}_{\text {lacSynth }}\right)$ were codon optimized for L. plantarum WCSF1 using http://www.jcat.de/ and synthesized by GeneArt ${ }^{\circledR}$ (life technologies). Promoter $\mathrm{P}_{\text {lacSynth }}$, T7 RNA polymerase and transcriptional terminator from L. buchneri CD034 D-lactate hydrogenase gene (AFS00145.1) [16] were also codon optimized as described above and synthesized by GeneArt ${ }^{\circledR}$. Nucleotide sequence of the codon optimized synthetic promoter/LacI repressor system is shown in Additional file 2 and T7 RNA polymerase is shown in Additional file 3.

\section{Strains and cultivation conditions}

Plasmids were constructed and propagated in E. coli Neb10 $\beta$ and clones were selected on LB agar plates with $100 \mu \mathrm{g} \mathrm{ml}^{-1}$ Ampicillin at $37{ }^{\circ} \mathrm{C}$. Sequence positive plasmids were amplified for transformation into plasmid cured L. plantarum 3NSH [17]. Clones were selected on either MRS agar plates with either $5 \mu \mathrm{g} \mathrm{ml}^{-1}$ chloramphenicol (CM), $5 \mu \mathrm{g} \mathrm{ml}^{-1}$ erythromycin (Ery) or both combined at $30^{\circ} \mathrm{C}$.

In liquid medium, $E$. coli strains were cultivated under agitation at $37^{\circ} \mathrm{C}$ in LB-medium. L. plantarum $3 \mathrm{NSH}$ was cultivated at $30{ }^{\circ} \mathrm{C}$ under oxygen limitation without agitation in MRS medium [7], supplemented with either $2 \%(w / v)$ D-glucose or $2 \%(w / v)$ D-galactose. B. megaterium DSMZ 319 was purchased from the "Deutsche Sammlung von Mikroorganismen und Zellkulturen" (Braunschweig, Germany) and was cultivated aerobically at $30{ }^{\circ} \mathrm{C}$ in nutrient medium. Antibiotics were added as required equally to solid media preparations.

Plasmid extraction was performed with plasmid purification kit for high-copy E. coli plasmids (NucleoSpin ${ }^{\circledR}$ Plasmid, Macherey-Nagel). After sequence verification, plasmids were used to transform L. plantarum $3 \mathrm{NSH}$ 
[44]. Plasmid isolation from $L$. plantarum 3NSH was performed according to Sambrook and Russel [39] with addition of $10 \mathrm{mg} \mathrm{ml}^{-1}$ lysozyme (Merck, 105281) and RNase (R6513, Sigma) to the resuspension buffer and incubation for $30 \mathrm{~min}$ at $37^{\circ} \mathrm{C}$ before cell lysis.

\section{Construction of the $\mathrm{P}_{\text {xyla }} /$ xylR-plasmid}

The $x y l R$ repressor/promoter fragment $\left(\mathrm{P}_{\mathrm{xylA}}\right)$ was amplified from genomic DNA of B. megaterium DSMZ 319. Therefore, an overnight culture was used for DNA extraction, with pre-treatment described for Gram-positive bacteria (DNeasy Blood and Tissue Kit, Quiagen). Primers B_mega_XylOP_out_F and B_mega_XylOP_R(SpeI, $S c a \mathrm{I}, \mathrm{BamHI}$ ) were used for amplification of the $x y l R$ repressor and $x y l A$ promoter genes with native RBS of xylA. Primers mCherry_w/o_RBS_XbaI and p256_miniori_for were used for amplification of reporter gene mCherry and Terminator $\mathrm{T}_{\text {ldh }}$ from L. casei BL23 (L-lactate dehydrogenase gene, LCABL-06930) from pCD256 $\mathrm{P}_{\text {lacSynth- }} \mathrm{mCherry}$ (Fig. 2h). Constructs were ligated at SpeI and $\mathrm{XbaI}$ complementary overhangs and amplified via a PCR using B_mega_XylOP_F_MfeI, KpnI and Tldh_ amp_PstI_R, digested with KpnI and PstI and cloned into the pCDLbu1 plasmid (Fig. 2a) with an origin of replication for E. coli and L. plantarum [43].

For generating expression constructs with identical RBS and spacer sequence, we exchanged the native RBS of $x y l A$ (Additional file 1) with the RBS sequence SOPT\#9 [47]. Nucleotide sequence of final $P_{x y l A}$ is shown in Fig. 1a. Therefore, we performed a continuous PCR around the ligated plasmid with phosphorylated primers B_mega_XylOP_newRBS_XbaI_Phos_R and mCherry_ Phos_F. After ligation, plasmid pCDLbu1_P $\mathrm{P}_{\mathrm{xyl}} \_\mathrm{mCherry}$ (Fig. 2b) was transformed into L. plantarum $3 \mathrm{NSH}$. For screening and sequencing purposes, primers $\mathrm{B}_{-}$mega XylOP_seq_F and B_mega_XylOP_seq_R were used.

\section{Construction of the $\mathrm{P}_{\mathrm{lacA}} / \mathrm{lacR}$-plasmid}

The plasmid pCDLbu1_P $\mathrm{P}_{\text {xylA_mCherry }}$ (Fig. 2b) was $\mathrm{SacI}$ and $\mathrm{XbaI}$ digested and fused with the LacR repressor/ promoter fragment $\left(\mathrm{P}_{\text {lacA }}\right)$. This fragment was amplified from genomic DNA of L. plantarum 3NSH (DNeasy Blood and Tissue Kit, Quiagen) with the primers LacI_ Lplant_F_SacI and LacI_Lplant_R_XbaI and sequenced (sequence of $\mathrm{P}_{\text {lacR }}$ and $\mathrm{P}_{\text {lacA }}$ is shown in Fig. 1b). BLASTn analysis showed $99 \%$ coverage (three mismatches) with the transcription regulator lacR gene of $L$. plantarum WCSF1. After ligation and transformation into E. coli Neb10 $\beta$, sequence positive plasmid pCDLbu1_P $\mathrm{P}_{\text {lacA- }}$ mCherry (Fig. 2c) was recovered and transformed into L. plantarum 3NSH. For screening and sequencing purposes, primers lacR_Gal_seq_R and lacR_Gal_seq_F were used.

\section{Construction of the $\mathrm{P}_{\text {lacsynth }} /$ /acl-plasmid}

Consecutive arrangement of synthetic $\mathrm{P}_{\text {lacSynth }} / \mathrm{LacI}$ regulon $\left(\mathrm{P}_{0234}\right.$ lacI_ $\left.\mathrm{P}_{2083}\right)$ is shown in Fig. 1c. The promoter from L. buchneri CD034 gene LBUCD034_0234 [16] was selected for transcription of lacI, encoding the E. coli derived codon optimized LacI repressor (Additional file 2). The promoter from L. buchneri CD034 gene LBUCD034_2083 [16] was selected for regulation of the reporter gene mCherry. Operator binding sites [30] were artificially inserted into $\mathrm{P}_{2083}$ sequence. Operator sequence $\mathrm{O}_{1}$ und $\mathrm{O}_{\text {id }}$ were adapted from $E$. coli [31]. Both constitutive L. buchneri CD034 promoters were identified within our group in previous promoter library experiments (data not shown).

The synthetic promoter was amplified from the synthetic GeneArt $^{\circledR}$ construct with primers PlacSynth_F_SacI_EcoRI and M13_R_NheI, digested with EcoRI and BamHI and ligated into EcoRI and BamHI digested pCD256 [43], receiving pCD256_P $\mathrm{P}_{\text {lac- }}$ Synth. This plasmid was amplified and proliferated in $E$. coli. Reporter gene mCherry was amplified from pCDLbu1 $\triangle E c_{-} \mathrm{P}_{11 \_}$mCherry [47] with primers mCherry RBS_XbaI and mCherry_R_BamHI, digested and ligated with pCD256_P $\mathrm{P}_{\text {lacSynth }}$ (cut XbaI and BamHI) plasmid. After transformation of E. coli and positive colony screening, pCD256_P $\mathrm{P}_{\text {lacSynth_mCherry (Fig. 2h) was }}$ recovered and the insert was amplified via PCR with primers PlacSynth_F_SacI_EcoRI and Tldh_amp_R_PstI, followed by digestion with EcoRI and PstI and ligation into digested pCDLbu1 (Fig. 2a) vector. The plasmid pCDLbu1_P lacSynth_mCherry (Fig. 2d) was amplified in E. coli and subsequently introduced into L. plantarum $3 \mathrm{NSH}$. For screening and sequencing purposes, primers mCherry_seq_R, mCherry_seq_F and Cat_seq 2_back were used.

\section{Construction of the T7 RNA polymerase based dual plasmid expression system}

DNA was amplified with the primers T7_RNAP_LP_ RBS and T7_RNAP_Lp_Term_R_SalI from a synthetic template. The fragment was $\mathrm{Xb} a \mathrm{I}$ and SalI digested and ligated into the $\mathrm{XbaI}$ and SalI digested pCD256_P $\mathrm{P}_{\text {lacSynth- }}$ mCherry plasmid (Fig. 2h), thus receiving the plasmid pCD256_P ${ }_{\text {lacSynth_T7RNAP (Fig. 2f). }}$.

The second plasmid (pCDLbu1 $\Delta E c_{-} \mathrm{P}_{\mathrm{T} 7}$ mCherry $\mathrm{T}_{\mathrm{T} 7 \text { Ery, Fig. 2g) was cloned stepwise. The reporter }}$ gene mCherry was amplified with primer M13_2_F and mCherry_R_BamHI from plasmid pCDLbu1_P lacSynthmCherry (Fig. 2d), digested with $\mathrm{Xba \textrm {I }}$ and BamHI and ligated into digested pET-30a plasmid (Table 2). Primers T7-Promoter_SacI and T7-Terminator_SalI were used to amplify the $\mathrm{P}_{\mathrm{T} 7} \mathrm{mCherry}_{-} \mathrm{T}_{\mathrm{T} 7}$ fragment from the established pET30a-mCherry plasmid. The erythromycin 
resistance gene $(e r m E)$ was amplified with primers ery_KasI_back and oripE194_seq_back from pE194 [18]. The ermE fragment was digested with $\mathrm{ClaI}$ to fuse it with the $\mathrm{Cla \textrm {I }}$ digested $\mathrm{P}_{\mathrm{T} 7-} \mathrm{mCherry} \mathrm{T}_{\mathrm{T} 7}$ fragment, followed by an enrichment PCR with primers ery_KasI_back and T7-Terminator_SalI. The resulting fragment was digested with KasI and BspEI and ligated into the KasI and XmaI digested plasmid pCDLbu1 [15], resulting in the plasmid pCDLbu1_ $\mathrm{P}_{\mathrm{T} 7-} \mathrm{mCherry}_{-} \mathrm{T}_{\mathrm{T} 7-}$ Ery. After amplification of the plasmid in E. coli JM109, E. coli specific sequences (pMB1 origin of replication and ampicillin resistance gene) were removed by PCR with primers Ery_F_NheI and M13_R_NheI. The PCR product of plasmid pCDLbu1 $\triangle E c_{-} \mathrm{P}_{\mathrm{T} 7 \_}$mCherry_ $\mathrm{T}_{\mathrm{T} 7 \_}$Ery (Fig. $2 \mathrm{~g}$ ) was digested with NheI, circularized by ligation and directly used to transform L. plantarum 3NSH [44].

Subsequent to sequence verification of a colony harboring plasmid pCDLbu1 $\Delta E c_{-} \mathrm{P}_{\mathrm{T} 7} \mathrm{mCherry}_{-} \mathrm{T}_{\mathrm{T} 7}$ Ery was used for establishing competent cells and transformed with plasmid pCD256_P $P_{\text {lacSynth_T7RNAP, resulting in }}$ a strain carrying two different expression vectors. After transformation, cells were selected on MRS plates with $5 \mu \mathrm{g} \mathrm{ml}^{-1} \mathrm{CM}$ and $5 \mu \mathrm{g} \mathrm{ml}^{-1}$ Ery. Colonies were screened for both expression plasmids verified by sequencing.

\section{Construction of negative controls}

For the inducible promoter/repressor constructs, a negative control plasmid was established by removing the whole inserted promoter/repressor fragment (plasmid with mCherry coding sequence and terminator; termed empty). The plasmid backbone, which is identical for every construct, was amplified with prim-

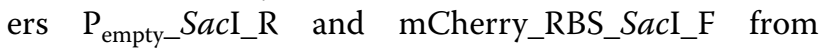
pCDLbu1_P $P_{\text {lacSynth- }}$ mCherry. The thereby established plasmid pCDLbu1_X_mCherry allows testing for mCherry expression, driven by possible read through from upstream regulatory sequences or possible unknown upstream promoter sequences.

As negative control for the T7 RNA polymerase dualplasmid system, we used a clone harboring only plasmid pCDLbu1_ $\mathrm{P}_{\mathrm{T} 7 \_} \mathrm{mCherry} \mathrm{T}_{\mathrm{T} 7}$ Ery. Thereby we tested if any other factors except T7 RNA polymerase contributes to mCherry expression.

\section{Induction conditions}

Over-night cultures were adjusted to $\mathrm{OD}_{600} 0.2$ in the respective liquid medium. After $2 \mathrm{~h}$ of growth at $30^{\circ} \mathrm{C}$ in the BioLector ${ }^{\circledR}$ micro-fermentation system, cultures were induced with the respective inducer 1:10 into each well, thus requiring that preparations of each inducer is tenfold concentrated in MRS-medium. Non-induced cells were prepared and tested simultaneously, but without the inducer (MRS medium only).
Tested sugars were used in the $\mathrm{D}(+)$-configuration and weighted as solids (weight) per volume medium $(w / v)$. The promoter $\mathrm{P}_{\mathrm{xylA}}$ was induced with xylose. Either 0.2, 1 or $2 \%$ xylose were used for induction. Therefore, 100 or $200 \mathrm{~g} \mathrm{l}^{-1} \mathrm{D}$-xylose was added to the medium (MRS $5 \mu \mathrm{g} \mathrm{ml}^{-1} \mathrm{CM}$ without glucose), heated in a water bath and sterile filtrated $(0.2 \mu \mathrm{m})$ and diluted accordingly. Other preliminary tested sugars such as fructose, arabinose, maltose, as well as galactose were prepared likewise.

The synthetic promoter $\mathrm{P}_{\text {lacSynth }}$ was induced with IPTG (VWR) and TMG (M8146, Sigma). Standard final concentration for IPTG was $1 \mathrm{mM}$. Therefore, $10 \mathrm{mM}$ IPTG was dissolved in selective MRS medium and 1:10 diluted into respective wells. For testing minimum and maximum induction concentrations, we used dilutions ranging from 0.1 to $5 \mathrm{mM}$ IPTG per well $(0.1,0.5,1,2$ and $5 \mathrm{mM}$ ). $17 \mathrm{mM}$ TMG was also tested for induction of $\mathrm{P}_{\text {lacSynth }}$ in selective MRS medium, as well as $2 \%$ lactose. For $\mathrm{P}_{\text {lacA }}$ standard conditions were selective MRS medium with $2 \%$ glucose, $2 \%$ maltose or $2 \%$ galactose or without additional carbon source and induction with 0.5 or $2 \%$ lactose after $2 \mathrm{~h}$.

\section{BioLector $^{\circledR}$ and Tecan reader measurements of intracellular mCherry expression}

Pre-measurements were performed in an Infinite ${ }^{\circledR}$ M1000 PRO Tecan microplate reader as described elsewhere [47]. The BioLector ${ }^{\circledR}$ micro-fermentation system (m2p-labs Germany) was also used for online measurement. Overnight cultures (in selective MRS medium with glucose or galactose) were diluted to an $\mathrm{OD}_{600}$ of 0.2 in the respective liquid medium. $720 \mu \mathrm{l}$ of each sample were pipetted per well of MTP-48-BOH FlowerPlate ${ }^{\circledR}$ (low pH, Lot No. 1408) or MTP-48-B FlowerPlate ${ }^{\circledR}$ (without optodes, Lot No. 1402) in quadruplicates and sealed with sterile tape adhesive sealing (Nunc, 732-2610). Samples were induced after $2 \mathrm{~h}$ of growth. Under sterile conditions $80 \mu \mathrm{l}$ of the particular inducer (tenfold concentrated in MRS medium) was pipetted into the respective well. $80 \mu \mathrm{l}$ MRS medium were added to non-induced samples and controls, and plates were covered again with sealing tape. Results were analyzed after $23 \mathrm{~h}$ using the BioLection 2.3.13 software using a previously described calibration curve for L. plantarum [47]. Calibration parameters were set for $30^{\circ} \mathrm{C}$ according to the manufacturer's recommendations.

\section{SDS-PAGE and Western blot analysis}

For Western blot analysis of intracellular mCherry (to compare the expression levels of under induced and non-induced conditions in selective MRS medium with glucose as carbon source) cells were collected at late 
exponential phase after $13 \mathrm{~h}$ of growth (dotted vertical line in Fig. 7). Recombinant purified mCherry with $\mathrm{His}_{6}$ tag (28.8 kDa) was purchased from BioVision (4993-100) and used as a positive control in defined concentrations per slot (25 and/or $50 \mathrm{ng}$ ). Per slot we applied samples corresponding to $5 \mu \mathrm{g}$ biomass each (calculated as described below). The reference strain (pCDLbu1 $\Delta E c_{-}$ $\mathrm{P}_{11 \_} \mathrm{mCherry)}$ was applied undiluted and 1:5 diluted for adaption to mCherry yields obtained by induction of the inducible promoters.

The pellet of $200 \mu$ culture was washed with PBS, centrifuged and pellet was re-suspended in $200 \mu \mathrm{l}$ PBS. OD 600 was measured of each sample. For analyzing equal amount of biomass $0.4 / \mathrm{OD}_{600}$ for each sample was calculated and used for intracellular analysis. A spatula tip of zirconium beads (BMBZ 100-250-17) was added to each sample, followed by alternating $30 \mathrm{~s}$ vortex and $30 \mathrm{~s}$ on ice; repeated for ten times. To remove cell debris and beads, samples were centrifuged at $4{ }^{\circ} \mathrm{C}$ full speed and supernatant was transferred into a fresh tube. A volume of $15 \mu$ l of each sample were mixed with $2 \times$ LDS loading buffer and incubated at $99{ }^{\circ} \mathrm{C}$ for $10 \mathrm{~min}$. Afterwards, $15 \mu \mathrm{l}$ per sample and $5 \mu \mathrm{l}$ protein ladder (Fermentas, SM0671) were loaded onto a NuPAGE ${ }^{\circledR} 12 \%$ BisTris gels and electrophoresis was run with MOPS buffer. The gel was blotted onto a PVDF membrane. Anti mCherry antibody (Biovision, 5993-100; 1:10.000) and AP-linked anti-rabbit secondary antibody (Sigma A9919; 1:20.000) were used for detection of mCherry. BCIP/NBT Color Development Substrate (Promega, S3771) was used for staining the blot.

\section{Additional files}

Additional file 1: Figure S1. Comparison of RBS and spacer sequence of $P_{\text {xylA (native RBS) }}$ and $P_{\text {xylA }}$.

Additional file 2: Figure S2. Sequence of the codon optimized version of the E. coli lacl repressor gene and PlacSynth.

Additional file 3: Figure S3. Sequence of the codon optimized version of the T7 RNA polymerase gene.

\section{Authors' contributions}

The work presented here was carried out in collaboration between all authors. S Heinl, RG and S Heiss defined the research theme and designed the experiments. S Heiss, AH, CT, MS and EE carried out the laboratory experiments. S Heiss analyzed the data, interpreted the results and prepared this manuscript with input, feedback and advice from S Heinl and RG. All authors read and approved the final manuscript.

\section{Acknowledgements}

This work was supported by the Christian Doppler Research Association, Vienna, Austria.

\section{Competing interests}

The authors declare that they have no competing interests.
Received: 23 September 2015 Accepted: 25 February 2016

Published online: 10 March 2016

\section{References}

1. Arasu MV, Jung MW, Kim dH, Ilavenil S, Jane M, Park HS, Al-Dhabi NA, Jeon BT, Choi KC. Enhancing nutritional quality of silage by fermentation with Lactobacillus plantarum. Indian J Microbiol. 2014;54:396-402.

2. Bhavsar AP, Zhao X, Brown ED. Development and characterization of a xylose-dependent system for expression of cloned genes in Bacillus subtilis: conditional complementation of a teichoic acid mutant. Appl Environ Microbiol. 2001;67:403-10.

3. Böhmer N, König S, Fischer L. A novel manganese starvation-inducible expression system for Lactobacillus plantarum. FEMS Microbiol Lett. 2013: doi:10.1111/1574-6968.12105.

4. Chaillou S, Pouwels PH, Postma PW. Transport of D-xylose in Lactobacillus pentosus, Lactobacillus casei, and Lactobacillus plantarum: evidence for a mechanism of facilitated diffusion via the phosphoenolpyruvate: mannose phosphotransferase system. J Bacteriol. 1999;181:4768-73.

5. D'Urzo N, Martinelli M, Nenci C, Brettoni C, Telford JL, Maione D. Highlevel intracellular expression of heterologous proteins in Brevibacillus choshinensis SP3 under the control of a xylose inducible promoter. Microb Cell Fact. 2013;12:12.

6. Dahl MK, Schmiedel D, Hillen W. Glucose and glucose-6-phosphate interaction with Xyl repressor proteins from Bacillus spp. may contribute to regulation of xylose utilization. J Bacteriol. 1995;177:5467-72.

7. De Man JC, Rogosa M, Sharpe ME. A medium for the cultivation of Lactobacilli. J Appl Microbiol. 1960;130-135.

8. del Rio B, Seegers JF, Gomes-Solecki M. Immune response to Lactobacillus plantarum expressing Borrelia burgdorferi OspA is modulated by the lipid modification of the antigen. PLoS One. 2010; doi:10.1371/journal. pone.0011199.

9. Douillard FP, de Vos WM. Functional genomics of lactic acid bacteria: from food to health. Microb Cell Fact. 2014;. doi:10.1186/1475-2859-13-S1-S8.

10. Feld LE, Bielak E, Hammer K, Wilcks A. Characterization of a small erythromycin resistance plasmid pLFE1 from the food-isolate Lactobacillus plantarum M345. Plasmid. 2009;61:159-70.

11. Fredriksen LC, Kleiveland R, Hult LT, Lea T, Nygaard CS, Eijsink VG, Mathiesen $\mathrm{G}$. Surface display of $\mathrm{N}$-terminally anchored invasin by Lactobacillus plantarum activates NF-kB in monocytes. Appl Environ Microbiol. 2012;78:5864-71.

12. Geoffroy MC, Guyard C, Quatannens B, Pavan S, Lange M, Mercenier A. Use of green fluorescent protein to tag lactic acid bacterium strains under development as live vaccine vectors. Appl Environ Microbiol. 2000;66:383-91.

13. Gösseringer R, Küster E, Galinier A, Deutscher J, Hillen W. Cooperative and non-cooperative DNA binding modes of catabolite control protein CcpA from Bacillus megaterium result from sensing two different signals. J Mol Biol. 1997;266:665-76.

14. Hasan N, Durr IF. Induction of beta-galactosidase in Lactobacillus plantarum. J Bacteriol. 1974;120:66-73.

15. Heinl S, Spath K, Egger E, Grabherr R. Sequence analysis and characterization of two cryptic plasmids derived from Lactobacillus buchneri CD034. Plasmid. 2011;66:159-68.

16. Heinl S, Wibberg D, Eikmeyer F, Szczepanowski R, Blom J, Linke B, Goesmann A, Grabherr R, Schwab H, Pühler A, Schlüter A. Insights into the completely annotated genome of Lactobacillus buchneri CD034, a strain isolated from stable grass silage. J Biotechnol. 2012;161:153-66.

17. Heiss S, Grabherr R, Heinl S. Characterization of the Lactobacillus plantarum plasmid pCD033 and generation of the plasmid free strain $L$. plantarum 3NSH. Plasmid. 2015;81:9-20.

18. Iordănescu S. Three distinct plasmids originating in the same Staphylococcus aureus strain. Arch Roum Pathol Exp Microbiol. 1976;35:111-8.

19. Jeffrey SR, Dobrogosz WJ. Transport of beta-galactosides in Lactobacillus plantarum NC2. Appl Environ Microbiol. 1990:56:2484-7.

20. Kerovuo J, Tynkkynen S. Expression of Bacillus subtilis phytase in Lactobacillus plantarum 755. Lett Appl Microbiol. 2000;30:325-9.

21. Kleerebezem M, Boekhorst J, van Kranenburg R, Molenaar D, Kuipers OP, Leer R, Tarchini R, Peters SA, Sandbrink HM, Fiers MW, Stiekema W, 
Lankhorst RM, Bron PA, Hoffer SM, Groot MN, Kerkhoven R, de Vries M, Ursing B, de Vos WM, Siezen RJ. Complete genome sequence of Lactobacillus plantarum WCFS1. Proc Natl Acad Sci USA. 2003;100:1990-5.

22. Korneli C, Biedendieck R, David F, Jahn D, Wittmann C. High yield production of extracellular recombinant levansucrase by Bacillus megaterium. Appl Microbiol Biotechnol. 2013;97:3343-53.

23. Ladero V, Ramos A, Wiersma A, Goffin P, Schanck A, Kleerebezem M, Hugenholtz J, Smid EJ, Hols P. High-level production of the low-calorie sugar sorbitol by Lactobacillus plantarum through metabolic engineering. Appl Environ Microbiol. 2007;73:1864-72.

24. Leer RJ, Christiaens H, Verstraete W, Peters L, Posno M, Pouwels PH. Gene disruption in Lactobacillus plantarum strain 80 by site-specific recombination: isolation of a mutant strain deficient in conjugated bile salt hydrolase activity. Mol Gen Genet. 1993;239:269-72.

25. Maischberger T, Mierau I, Peterbauer CK, Hugenholtz J, Haltrich D. Highlevel expression of Lactobacillus beta-galactosidases in Lactococcus lactis using the food-grade, nisin-controlled expression system NICE. J Agric Food Chem. 2010;58:2279-87.

26. Malten M, Hollmann R, Deckwer WD, Jahn D. Production and secretion of recombinant Leuconostoc mesenteroides dextransucrase DsrS in Bacillus megaterium. Biotechnol Bioeng. 2005;89:206-18.

27. Marbach A, Bettenbrock K. lac operon induction in Escherichia coli: Systematic comparison of IPTG and TMG induction and influence of the transacetylase LacA. J Biotechnol. 2012;157:82-8.

28. Nguyen TT, Nguyen HM, Geiger B, Mathiesen G, Eijsink VG, Peterbauer CK, Haltrich D, Nguyen TH. Heterologous expression of a recombinant lactobacillal $\beta$-galactosidase in Lactobacillus plantarum: effect of different parameters on the sakacin P-based expression system. Microb Cell Fact. 2015;14:30.

29. Novick RP. Plasmid incompatibility. Microbiol Rev. 1987;51:381-95.

30. Oehler S, Amouyal M, Kolkhof P, von Wilcken-Bergmann B, Müller-Hill B. Quality and position of the three lac operators of E. coli define efficiency of repression. EMBO J. 1994;13:3348-55.

31. Oehler S, Eismann ER, Krämer H, Müller-Hill B. The three operators of the lac operon cooperate in repression. EMBO J. 1990;9:973-9.

32. Oh Y, Varmanen P, Han XY, Bennett G, Xu Z, Lu T, Palva A. Lactobacillus plantarum for oral peptide delivery. Oral Microbiol Immunol. 2007;22:140-4.

33. Pal G, Srivastava S. Scaling up the production of recombinant antimicrobial plantaricin E from a heterologous host, Escherichia coli. Probiotics Antimicrob Proteins. 2015; doi:10.1007/s12602-015-9193-7.

34. Pavan S, Hols P, Delcour J, Geoffroy MC, Grangette C, Kleerebezem M, Mercenier A. Adaptation of the nisin-controlled expression system in Lactobacillus plantarum: a tool to study in vivo biological effects. Appl Environ Microbiol. 2000;66:4427-32.

35. Posno M, Heuvelmans PT, van Giezen MJ, Lokman BC, Leer RJ, Pouwels $\mathrm{PH}$. Complementation of the inability of Lactobacillus strains to utilize D-xylose with D-xylose catabolism-encoding genes of Lactobacillus pentosus. Appl Environ Microbiol. 1991;57:2764-6.

36. Rossi F, Capodaglio A, Dellaglio F. Genetic modification of Lactobacillus plantarum by heterologous gene integration in a not functional region of the chromosome. Appl Microbiol Biotechnol. 2008;80:79-86.
37. Rossi F, Rudella A, Marzotto M, Dellaglio F. Vector-free cloning of a bacterial endo-1,4-beta-glucanase in Lactobacillus plantarum and its effect on the acidifying activity in silage: use of recombinant cellulolytic Lactobacillus plantarum as silage inoculant. Antonie Van Leeuwenhoek. 2001;80:139-47.

38. Rud I, Jensen PR, Naterstad K, Axelsson L. A synthetic promoter library for constitutive gene expression in Lactobacillus plantarum. Microbiology. 2006;152:1011-9.

39. Sambrook J, Russel DW. Molecular cloning: a laboratory manual. 3rd ed. New York: Cold Spring Harbor Laboratory; 2001.

40. Schmiedel D, Kintrup M, Küster E, Hillen W. Regulation of expression, genetic organization and substrate specificity of xylose uptake in Bacillus megaterium. Mol Microbiol. 1997;23:1053-62.

41. Schultz M, Veltkamp C, Dieleman LA, Grenther WB, Wyrick PB, Tonkonogy SL, Sartor RB. Lactobacillus plantarum 299 V in the treatment and prevention of spontaneous colitis in interleukin-10-deficient mice. Inflamm Bowel Dis. 2002;8:71-80.

42. Siezen RJ, van Hylckama Vlieg JE. Genomic diversity and versatility of Lactobacillus plantarum, a natural metabolic engineer. Microb Cell Fact. 2011;10(Suppl 1):S3.

43. Spath K, Heinl S, Egger E, Grabherr R. Lactobacillus plantarum and Lactobacillus buchneri as expression systems: evaluation of different origins of replication for the design of suitable shuttle vectors. Mol Biotechnol. 2012;52:40-8

44. Spath K, Heinl S, Grabherr R. Direct cloning in Lactobacillus plantarum: electroporation with non-methylated plasmid DNA enhances transformation efficiency and makes shuttle vectors obsolete. Microb Cell Fact. 2012;11:141.

45. Stammen S, Müller BK, Korneli C, Biedendieck R, Gamer M, Franco-Lara E, Jahn D. High-yield intra- and extracellular protein production using Bacillus megaterium. Appl Environ Microbiol. 2010;76:4037-46.

46. Sørvig E, Mathiesen G, Naterstad K, Eijsink VG, Axelsson L. High-level, inducible gene expression in Lactobacillus sakei and Lactobacillus plantarum using versatile expression vectors. Microbiology. 2005;151:2439-49.

47. Tauer C, Heinl S, Egger E, Heiss S, Grabherr R. Tuning constitutive recombinant gene expression in Lactobacillus plantarum. Microb Cell Fact. 2014;13:150.

48. Wilson CJ, Zhan H, Swint-Kruse L, Matthews KS. The lactose repressor system: paradigms for regulation, allosteric behavior and protein folding. Cell Mol Life Sci. 2007;64:3-16.

49. Wilson TH, Kashket ER. Isolation and properties of thiogalactoside transacetylase-negative mutants of Escherichia coli. Biochim Biophys Acta. 1969;173:501-8.

50. Zhang Y, Vadlani PV. Lactic acid production from biomass-derived sugars via co-fermentation of Lactobacillus brevis and Lactobacillus plantarum. J Biosci Bioeng. 2015;119:694-9.

\section{Submit your next manuscript to BioMed Central and we will help you at every step:}

- We accept pre-submission inquiries

- Our selector tool helps you to find the most relevant journal

- We provide round the clock customer support

- Convenient online submission

- Thorough peer review

- Inclusion in PubMed and all major indexing services

- Maximum visibility for your research

Submit your manuscript at www.biomedcentral.com/submit

\section{Biomed Central}

